\title{
Modelling the Static Response of Unaged Adhesively Bonded Structures
}

\author{
S. Sugiman ${ }^{\mathrm{a}}$, A.D. Crocombe ${ }^{\mathrm{b}, *}$ I.A. Aschroft ${ }^{\mathrm{c}}$ \\ ${ }^{a}$ Department of Mechanical Engineering, Faculty of Engineering, University of Mataram, Mataram, West \\ Nusa Tenggara, 83125, Indonesia. \\ ${ }^{\mathrm{b}}$ Division of Mechanical, Medical and Aerospace Engineering, Faculty of Engineering and Physical Sciences, \\ University of Surrey, Guildford, Surrey, GU2 7XH, UK. \\ ${ }^{\mathrm{c}}$ Wolfson School of Mechanical and Manufacturing Engineering, Loughborough University, Loughborough, \\ UK.
}

\begin{abstract}
A cohesive zone model has been used to model the progressive damage in adhesively bonded aluminium monolithic single lap joints and laminated doublers. The backface strain technique was used to monitor the damage process in the adhesive layer and was also key in the calibration of a unique set of cohesive zone properties in the single lap joint. Further, this backface strain technique has been successfully used to assess the effect of position of cohesive element, substrate plasticity, the traction and fracture energy and the adhesive fillet in a monolithic single joint. The calibrated cohesive properties have then been successfully used to predict the static strength and backface strain response of the doubler in bending.
\end{abstract}

\section{Keywords: Aluminium alloys, cohesive zone modelling, damage}

\section{Introduction}

First introduced by Barenblatt [1,2] for metals, the cohesive zone model (CZM) has been extensively used to simulate the progressive damage (initiation and propagation) in adhesively bonded joints. When predicting the failure load and failure process of adhesively bonded joints the CZM properties should be determined properly. The main parameters of a CZM are the traction and the fracture energy. Some researchers [3-5]

* Corresponding author. Phone: +44 1483 689194, E-mail address: a.crocombe@surrey.ac.uk 
determined the normal and shear fracture energy from wedge double cantilever beam (DCB) and end notch flexure (ENF) specimens respectively, while the normal and shear tractions were obtained from the tensile bulk adhesive and the torsion butt joint respectively. They reported good agreement between the numerical and the experiment results. However, the damage process in the adhesive layer was not investigated. Other methods to determine the CZM parameters as reported by da Silva and Campilho [6] are direct and inverse methods and both approaches are able to give an accurate predicted response of the material system studied.

Another aspect of the cohesive zone model is the shape of the unloading response. Many shapes of CZM have been proposed and used in modelling of fracture including exponential, polynomial, trapezoidal and bilinear. A comparison of those models has been made and reported in literature. Chandra et al. (2002) studied the bilinear and exponential shape of the CZM on the prediction of silicon carbide fibre push out in a metal matrix and found that the shape of CZM has a significant effect on the load-displacement response. Here, although the geometry is small, the bulk stiffness is very high. Volokh (2004) studied the effect of the CZM shape (bilinear, parabolic, sinusiodal and exponential) on the predicted load-displacement response of a rigid block peel specimen and also found that CZM shape has a significant effect on the load-displacement response. Alfano (2006) studied a bilinear, an exponential, a trapezoidal and a parabolic shape of CZM on the predicted response of an aluminium DCB and a steel compact tension specimen and reported that for a typical DCB (i.e. made of aluminium with thickness of $3 \mathrm{~mm}, \mathrm{E}=70$ GPa), the shape of CZM does not have a significant effect on the predicted loaddisplacement response. However, with the increase of specimen geometry (thickness of 60 $\mathrm{mm}$ ) a variation of predicted load-displacement response occurred at the vicinity of peak 
load (bilinear and exponential were close but trapezoidal and linear parabolic were higher than both bilinear and exponential). When the thickness of specimen was $100 \mathrm{~mm}$ and the substrate stiffness increased from $70 \mathrm{GPa}$ (aluminium) to $210 \mathrm{GPa}$ (steel) a variation of predicted peak load between bilinear and exponential, and trapezoidal and linear parabolic of up to $15 \%$ was observed. Further, this variation was also observed in the mode II pull out test made of aluminium where extensional stiffness is involved rather than flexural stiffness. The length of cohesive zone increased with the increase of geometry and stiffness (from approximately of $1.5 \mathrm{~mm}$ for aluminium DCB with thickness of $3 \mathrm{~mm}$ to approximately of $12 \mathrm{~mm}$ for thickness of $60 \mathrm{~mm}$, while for steel compact tension, the cohesive zone length was approximately $23 \mathrm{~mm}$. Thus, the shape of CZM has a more significant effect when the geometry and bulk stiffness is relatively large resulting in a large cohesive zone length as well.

A useful method for monitoring the damage process in the adhesive layer of a bonded joint is the backface strain technique. This technique was initially introduced by Abe and Satoh [10] to monitor the crack initiation and propagation in welded structures. Then that technique was employed in adhesively bonded joints by Zhang et al. [11] to monitor damage propagation by placing the strain gauges (SG) on the substrate in the overlap region. Further, Crocombe et al. [12] studied the backface strain technique in adhesively bonded joints numerically. It was found that when there was no crack in the adhesive layer, the backface strain reached a maximum just outside the overlap and when a crack was introduced at one end and propagated, the maximum backface strain followed the crack tip. Further, this maximum backface strain depended on the type of substrate and the length of gauges. 
Finding a unique set of CZM parameters is a challenge. Many sets of CZM properties can predict the failure load of a joint [13], however these will not all provide the correct damage evolution and thus their use is questionable. This paper presents experimental and numerical studies on Al 2024-T3 monolithic single lap joints (MSLJ) and laminated doublers, both bonded using FM 73M OST, to calibrate and validate CZM properties respectively, using both the load and the damage to provide a unique set of CZM parameters. Progressive damage finite element modelling is used to predict the static response of the MSLJ and then validated using the laminated doublers. The effects of factors such as position of the CZM in the adhesive layer, traction and fracture energy of the CZM and mesh size of the cohesive element, substrate plasticity and fillet on the static response are investigated. The backface strain-load response was utilised as a means of calibrating the cohesive zone properties and investigating the effect of the factors above. The calibrated CZM has been successfully used to predict the static response (including damage evolution) of laminated doublers loaded in bending (LDB).

\section{Experimental method}

\subsection{Monolithic single lap joint specimen and testing}

The substrates for the single lap joints were Al 2024-T3 with a thickness of $4.7 \mathrm{~mm}$. Details of the specimen is shown in Fig. 1. Prior to being bonded, the surface of the aluminium substrate was treated using chromic acid etching (CAE) followed by phosphoric acid anodising (PAA) and then applying the corrosion inhibiting primer BR127. This treatment process was conducted at Airbus, Bristol, UK. Adhesive FM 73M OST was used to bond these substrates. Two layers of FM 73M OST approximately (30 x 5) mm were cut from a sheet of FM 73M OST and then laid up on the aluminium surfaces. A light pressure was applied to remove air bubbles and to ensure the adhesive made contact with the aluminium surface. The two aluminium substrates were then clamped 
together in a fixture and a pressure of 0.3 MPa was applied to the bondline. Steel spacers of thickness of $4.9 \mathrm{~mm}$ were used to control the adhesive thickness. The specimens were cured in an oven at $120^{\circ} \mathrm{C}$ for 1 hour as recommended by Cytec [14].

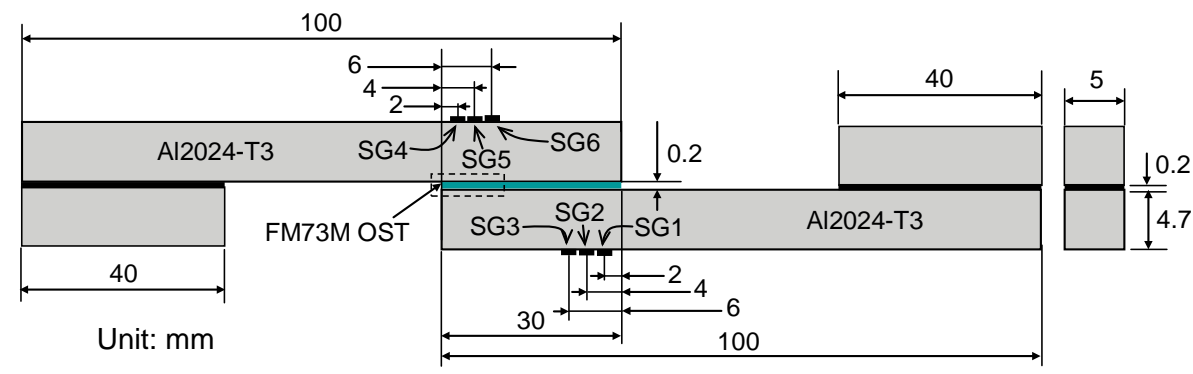

Fig. 1 Dimension of MSLJ and the strain gauge locations on the substrate (not to scale). The dashed box indicates the location of images were taken, shown in Fig. 3b.

Before testing, strain gauges were attached to the aluminium substrate to monitor the damage in adhesive layer during testing. At least one strain gauge was attached on the backface of each substrate. The centre of the first strain gauge was located $2 \mathrm{~mm}$ inside from the overlap edge (Fig. 1), following published guidance [12]. Additional strain gauges were used to obtain more information on the damage propagation.

Static tensile testing was carried out using a $50 \mathrm{kN}$ Instron 1341 servo-hydraulic machine. The specimen was gripped over a $40 \mathrm{~mm}$ length, and the test rate was $0.1 \mathrm{~mm} / \mathrm{min}$. Video microscopy was also used to monitor the damage during the test. The strain gauges were connected to amplifiers and a data logger to record the strains.

\subsection{Laminated doubler specimen and testing}

The laminate was made of aluminium 2024-T3 bonded with the same adhesive used in the MSLJ. The laminate consisted of 6 layers of aluminium and 5 layers of adhesive, with 
thicknesses of approximately $1.6 \mathrm{~mm}$ and $0.15 \mathrm{~mm}$ respectively. The stringer bonded onto the laminate panel was aluminium 7055-T7751. The bonded stringer is a typical structural configuration and the ends of the stringer form a stress concentration and a possible location of failure. The surface treatment and bonding process for this joint was the same as with the MSLJ. The length and the thickness of the stringers varied from 85-93 mm and 9.5-10.5 mm respectively. The thickness of adhesive layer attaching the stringer to the laminated substrate (stringer bondline) was not constant along the length due to the curvature of the laminate. It was thinner at the edge (around $0.1 \mathrm{~mm}$ ) and thicker at the centre (around $0.2 \mathrm{~mm}$ ). The test specimen and dimensions are shown in Fig. 2.

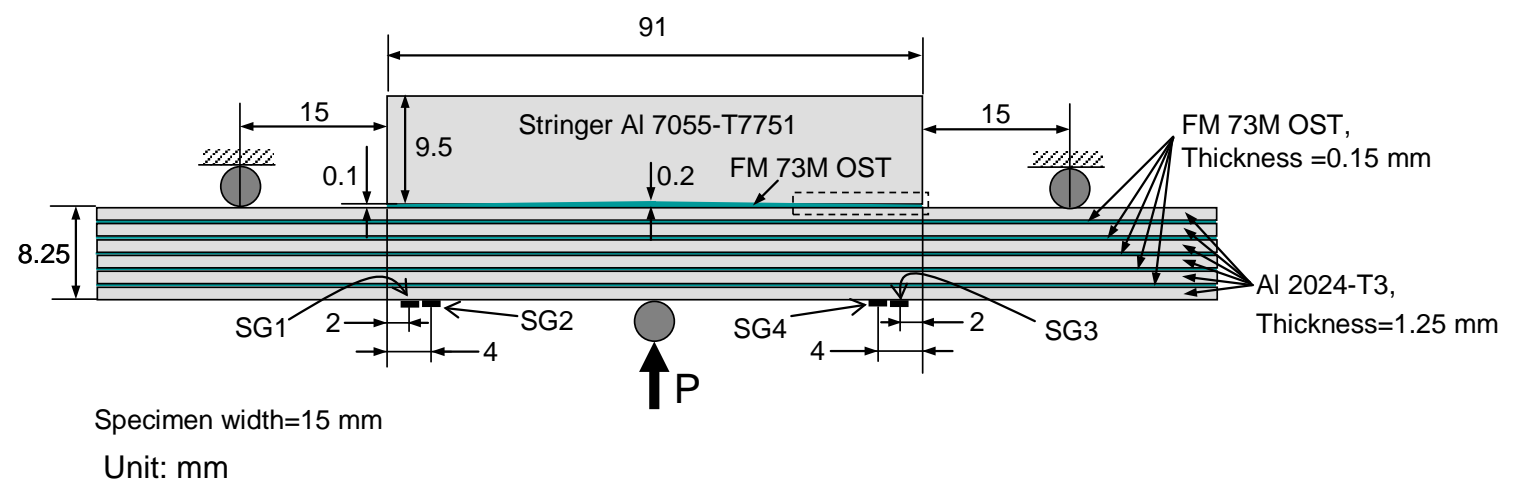

Fig. 2 Dimensions of the LDB joints and the strain gauge locations on the laminate (not to scale). The dashed box indicates the location where images shown in Fig. 5b were taken,.

The laminated doublers were tested in three point bending (LDB) using an Instron 8511 (20 kN servo-hydraulic test machine) with the load $(P)$ applied at the centre. The distance from the support roller to the edge of the stringer was kept constant at $15 \mathrm{~mm}$ regardless of the stringer length (see Fig. 2). This was sufficient distance to provide access for the in-situ video microscope and ensured that at the overlap ends the relation between the force and the moment was the same in all specimens. The LDB tests were performed at a rate of 0.5 $\mathrm{mm} / \mathrm{min}$. The failure process during the test was monitored visually and using a video microscope connected to a computer. In addition, strain gauges were attached on the laminate to monitor the damage evolution in the adhesive layer. The location of the first 
strain gauge centre was $2 \mathrm{~mm}$ inside both overlap ends (see Fig. 2). Multiple gauges were used to characterise the damage evolution better.

\section{Experimental results}

\subsection{Static response of monolithic single lap joint}

Four samples of MSLJ were tested and the average static strength was $3.93 \pm 0.08 \mathrm{kN}$. The specimen failure surfaces are mostly cohesive in the adhesive. The damage, in general, started at the end of the overlap where a high stress concentration exists. This damage then increased and propagated to the centre of the joints with an increase of loading. Fig. 3a shows a typical load-displacement response with images of adhesive layer damage at selected points. As seen in Fig. 3a, at point $2(3 \mathrm{kN})$, the damage has propagated along the adhesive layer (see Fig. 3b, shown by the arrow). The damage continued to propagate faster as the load-displacement slope reduced (from point 2 to point 3). When the load reached the ultimate value (point 4), the damage had propagated from the end of the overlap and visible fully formed cracks were observed (see Fig. 3b, image 4), and the damage zone length was approximately $4.7 \mathrm{~mm}$. Initial damage in the adhesive layer was indicated by a whitening zone, and the subsequent cracks showed as dark. The crack grew faster after the peak load due to the progressive damage and the load dropped sharply (point 5). 
(a)

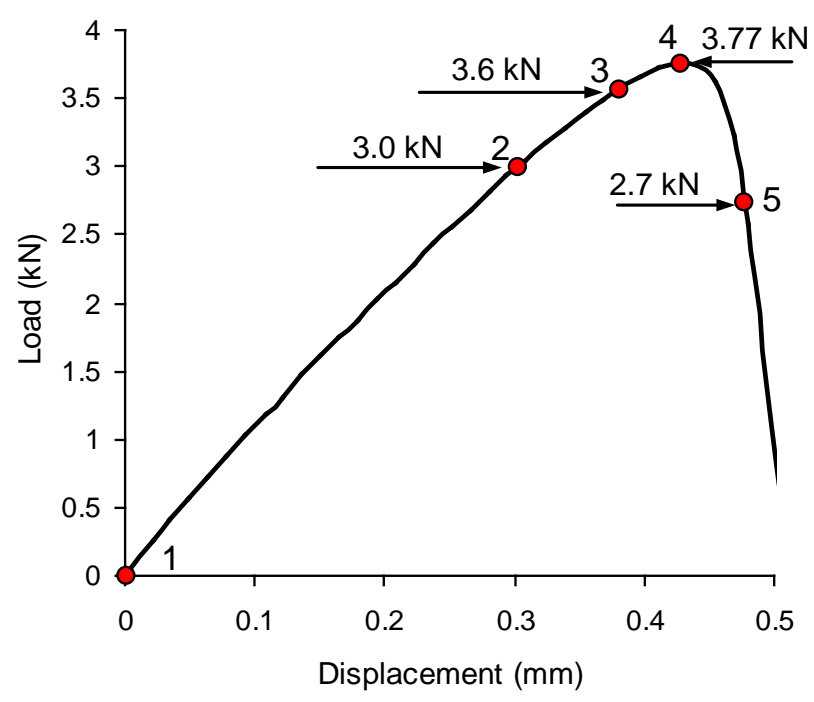

(b)

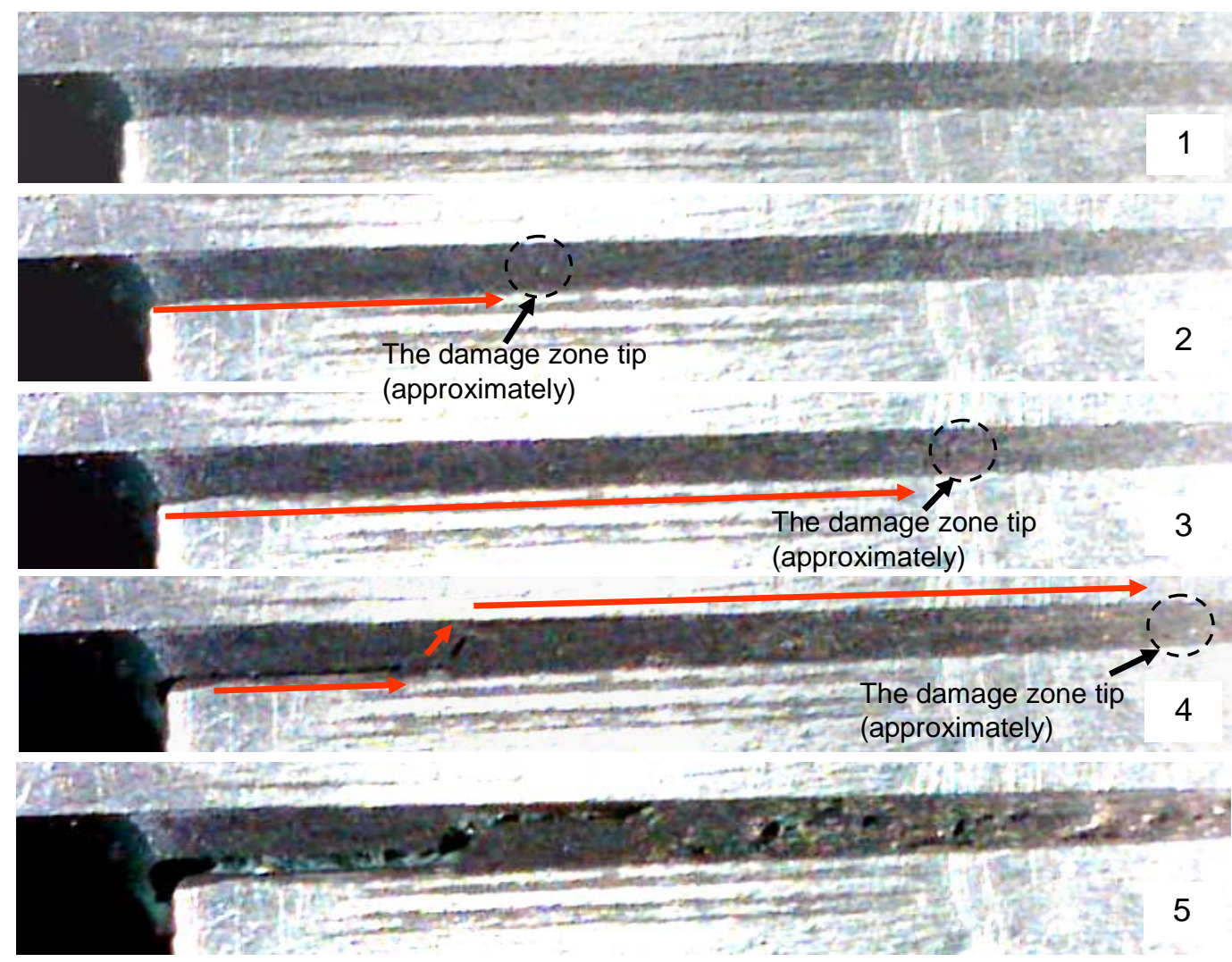

$\stackrel{0.5 \mathrm{~mm}}{.}$

Fig. 3 Static failure process in MSLJ (a) selected point in load-displacement curve, (b) images of the damage.

Careful observation has been made to correlate (synchronise) the process of damage with the load-displacement (and backface strain) response (see Fig. 2). Based on the loaddisplacement (and backface strain) curve, there are three distinct regions related to the 
damage process as seen in Fig. 4. Region I is the undamaged region, a small region, up to dashed line 1 (approximately $1 \mathrm{kN}$ ), where no damage could be observed in the entire adhesive layer. Region II is damage initiation and propagation in a stable manner. This damage initiated early as the overlap is relatively long and local damage can occur significantly before global failure occurs. This starts from dashed line 1 up to dashed line 2, at a load of approximately $2.6 \mathrm{kN}$. Damage in this region is not clearly seen in Fig. 3b as the colour of the adhesive surface prevents the whitening zone being seen. Evidence of this region is clearly seen in similar, but environmentally aged, adhesive joints [15]. The slope of load-displacement (and backface strain) curve slightly decreases as the adhesive in the corner region of the overlap starts to damage. The damage then increases and propagates to the centre of the joints until sudden failure occurs. Region III lies beyond the dashed line 2 until the final failure. The beginning of region III is indicated by the changing slope of the load-displacement (backface strain) curve before the peak point. The damage in the adhesive layer propagates faster and can be clearly seen in Fig. 3b, at point 3 and 4 . The substrate close to the end of overlap starts to deform plastically around point 2, however the plastic deformation is hard to detect visually and finite element modelling needs to be carried to clarify this.

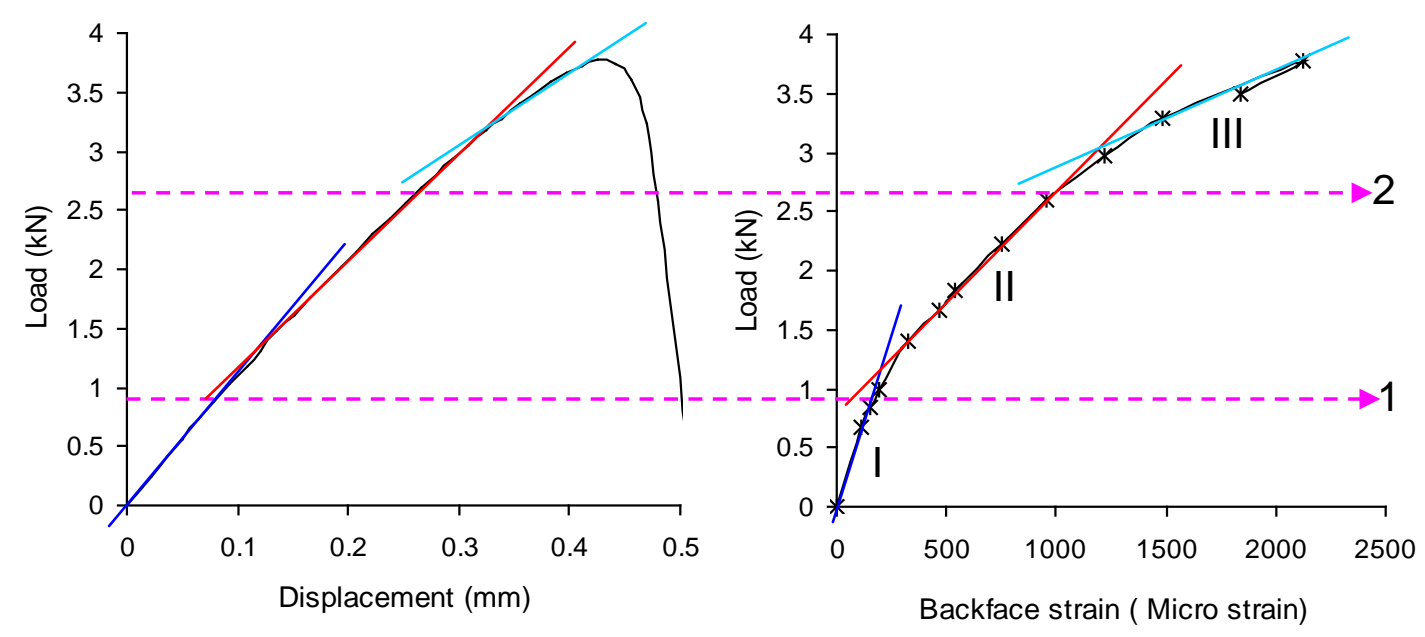


Fig. 4 The comparison of (a) load-displacement curve and (b) load-backface strain curve as a means of identifying adhesive damage. The backface strain reading is taken from the strain gauge located $2 \mathrm{~mm}$ inside the end of the overlap (Fig.1). Symbols $*$ represent experimentally measured backface strain data.

Comparison between the load-displacement and the load-backface strain curves related to the damage process is shown in Fig. 4. The transition from region I to region II in the load-backface strain is clearer than in the load-displacement response and so is the transition from region II to region III. This indicates that the load-backface strain is a better indicator of the damage process in statically loaded joints than the load-displacement response.

\subsection{Static response of laminated doubler in bending}

The average static strength of the three LDB specimens tested was $5.05 \pm 0.01 \mathrm{kN}$. The failure surface was fully cohesive in the adhesive. The failure process was observed using an in-situ video microscope in conjunction with backface strain technique. Fig. 5(a) shows the load and backface strain history for a typical joint. Only SG4 (see Fig. 2) is illustrated. The labels 1-5 on Fig. 5a indicate when the images, shown in Fig. 5(b), were taken during the testing. At point 1, which corresponds to $1.99 \mathrm{kN}$, no visible damage (crack) was observed. The strain increased stably until point 2 (3.7 kN), however some whitening was noticed near the fillet, extending about $1 \mathrm{~mm}$ from the end of overlap (it may be difficult to see the whitening, which is located inside the dashed ellipse). The whitening region was seen more clearly with increasing load (around $4.7 \mathrm{kN}$, at point 3 ) and tiny voids (crack initiation) may just be seen, around $1 \mathrm{~mm}$ from the overlap end. A possible cause of this whitening may be crazing or some other form of micro-damage in the adhesive. Starting from this point the load-time curve became nonlinear and the strain increased rapidly as the 
load rose to its maximum value $(5.11 \mathrm{kN})$, at point 4 . At this point, visible damage was observed, which was seen as voids and a whitening zone extending at least $7 \mathrm{~mm}$ from the overlap end (possibly longer but outside the frame of the video-microscope). After point 4, the crack grew in an unstable manner toward the centre and into the fillet (point 5). It seems that the fibre carrier in the adhesive may have provided limited bridging of the crack. The load and strain also dropped abruptly followed by a period of flattening until the damage reached the centre of the joint. 
(a)

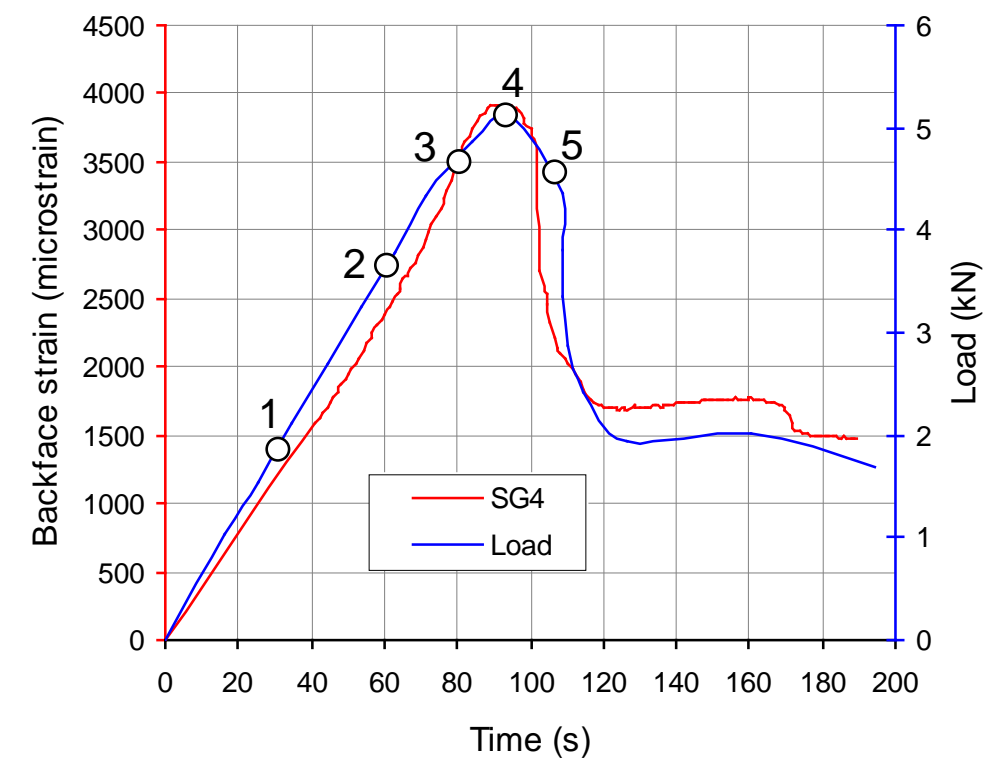

(b)
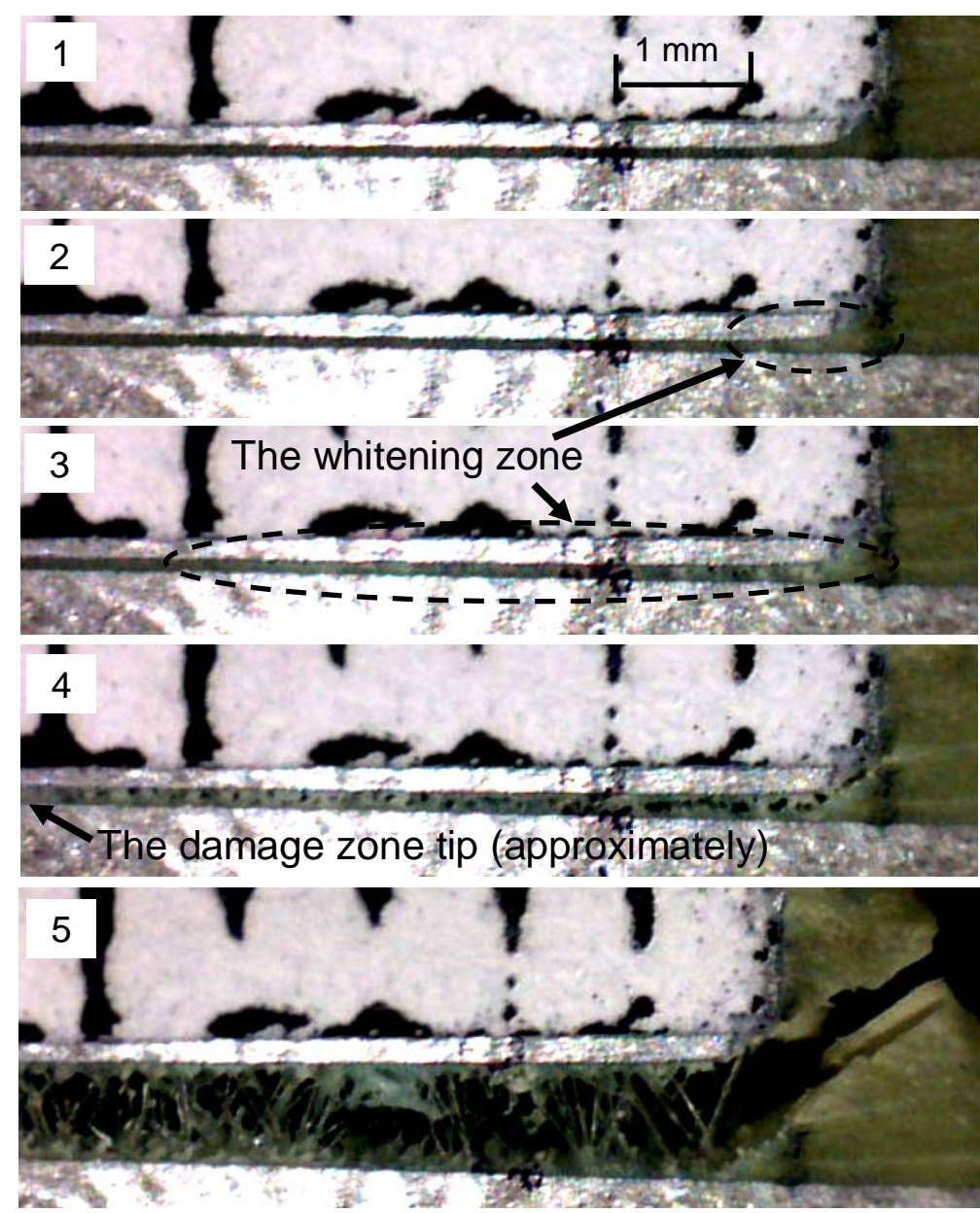

Fig. 5 The damage process of LDB. (a) Showing points of load and corresponding backface strain where images were taken. The sign of the actual strain is reversed. (b) Showing the damage process in the adhesive layer. The white seen on the upper (stringer) substrate is a scale attached to facilitate measurement of the crack length. 


\section{Finite element modelling}

In a cohesive zone law, the cohesive stress usually increases rapidly with the increasing separation until it reaches a maximum value and then decreases more gradually and reaches zero when complete separation occurs. ABAQUS ${ }^{\circledR}$ finite element code [16] has the capability to implement the cohesive zone model as a bilinear traction-separation law. A bilinear traction-separation law consists of three main parameters; the elastic stiffness $(K)$, critical traction $\left(T_{\max }\right)$, and fracture energy $\left(G_{C}\right)$ as shown schematically in Fig. 6a. Parameters, $\delta_{o}$ and $\delta_{f}$ (Fig. 6a), are the separation at the critical traction and at the complete failure respectively, whilst $\delta_{n}^{f}, \delta_{s}^{f}$, and $\delta_{m}^{f}$ (Fig. 6b) indicate the normal, shear and mixed mode directions of the complete separation, respectively. The critical traction and fracture energy are related to damage initiation and damage evolution, respectively.

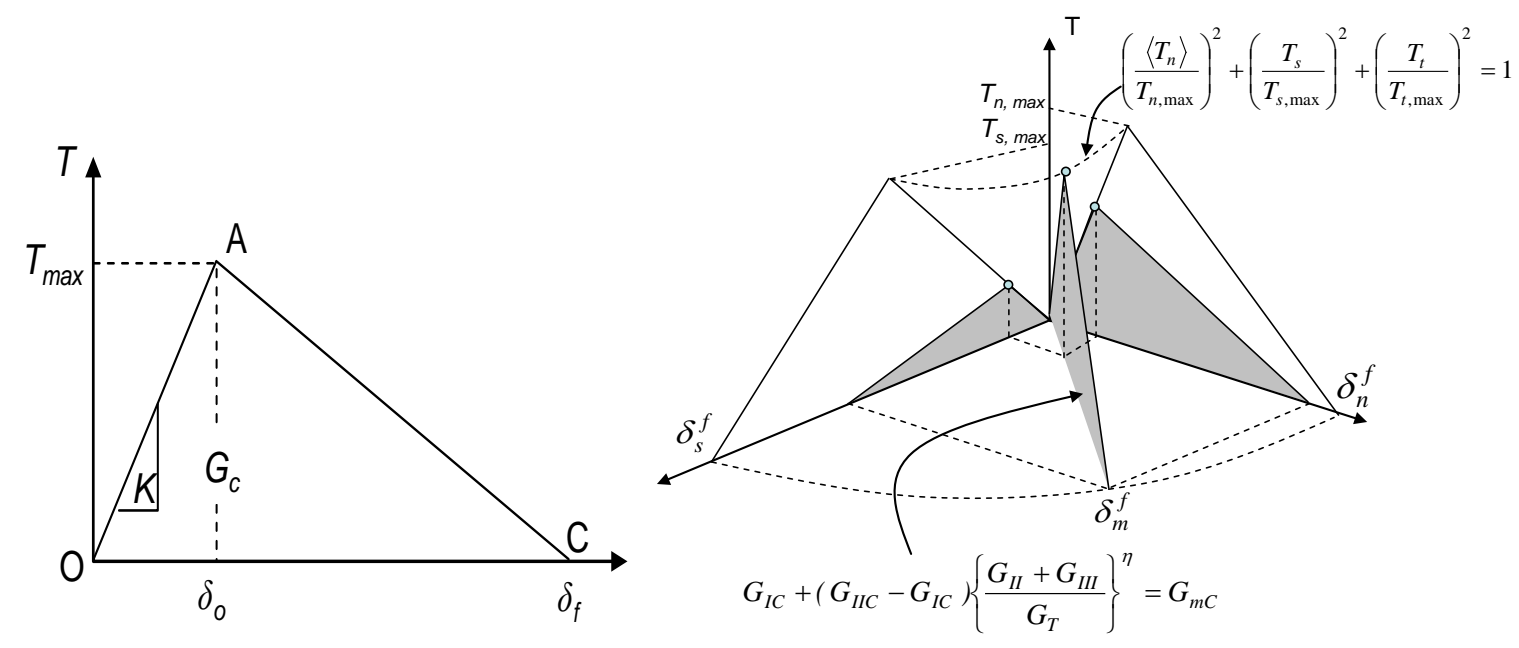

(a)

(b)

Fig. 6 Schematic (a) bilinear traction-separation cohesive zone model, (b) mixed mode cohesive zone model in ABAQUS ${ }^{\circledR}$.

In this FE modelling, damage initiation (point A in Fig. 6a) was determined using the quadratic nominal stress criterion, Eq. (1). 


$$
\left\{\frac{\left\langle T_{n}\right\rangle}{T_{n, \max }}\right\}^{2}+\left\{\frac{T_{s}}{T_{s, \text { max }}}\right\}^{2}+\left\{\frac{T_{t}}{T_{t, \text { max }}}\right\}^{2}=1
$$

where subscripts $n, s$ and $t$ indicate normal and first and second shear directions of traction (T) respectively. The Macaulay operator \langle\rangle denotes that the compressive stress does not induce damage.

Damage evolution results in a progressive reduction in material stiffness. The stress components during damage evolution are reduced following Eq. (2)-Eq. (4).

$$
\begin{aligned}
& T_{n}= \begin{cases}(1-D) \bar{T}_{n} & \bar{T}_{n} \geq 0 \\
0 & \text { otherwise }\end{cases} \\
& T_{s}=(1-D) \bar{T}_{s}, \\
& T_{t}=(1-D) \bar{T}_{t},
\end{aligned}
$$

where $\bar{T}_{n}, \bar{T}_{S}$ and $\overline{T_{t}}$ are the stress components predicted by the elastic traction-separation behaviour for the current strains without damage, $D$ is the scalar damage variable of the cohesive element. During damage, $D$ evolves monotonically from 0 (undamaged material, at the damage initiation) to 1 (when the material is fully damaged).

The energy based mixed mode damage evolution law suggested by Benzeggagh and Kenane [17] given in Eq. (5) was used in this work.

$$
G_{I C}+\left(G_{I I C}-G_{I C}\right)\left\{\frac{G_{I I}+G_{I I I}}{G_{T}}\right\}^{\eta}=G_{m C}
$$


where $G_{T}=G_{I}+G_{I I}+G_{I I I}$ and $\eta$ is a material parameter. $G_{I C}, G_{I I C}$ and $G_{m C}$ are fracture energies for mode I and mode II and mixed mode loading respectively. $G_{I}, G_{I I}$ and $G_{I I I}$ are the strain energy release rates (SERR) for the mode I, mode II and mode III respectively. In this criterion, fracture energy for first shear (mode II) and second shear directions (mode III) are the same, $G_{\text {IIC }}=G_{\text {IIIC }}$. The assumed value of $G_{I I I C}$ may influence the results, but with a lack of reliable data, this is an aspect for future study. A schematic of the mixed mode damage evolution is shown in Fig. 6b.

\subsection{Calibrating the CZM in single lap joints}

This section presents the progressive damage modelling of Al 2024-T3 monolithic single lap joints bonded using FM 73M OST. A bilinear traction-separation law (see Fig. 6) was used in the FE modelling. As the experimental failure mode was cohesive in the adhesive layer, the cohesive element was placed in the middle of adhesive layer, while the remaining adhesive was modelled using continuum elements (see Fig. 7b). However, the effect of cohesive element position (Fig 7a) will be discussed in section 4.1.2. The maximum normal traction $\left(T_{n, \max }\right)$ was obtained from the bulk adhesive tensile test, whilst the maximum first and second shear traction $\left(T_{s, \max }\right.$ and $\left.T_{t, \max }\right)$ were determined from this value assuming a von Mises equivalent stress. The normal elastic stiffness $\left(K_{n}\right)$ was obtained from the adhesive Young's modulus $(E)$ divided by the cohesive element thickness $\left(t_{c z m}\right)$. Similarly, the first shear elastic stiffness $\left(K_{s}\right)$ and the second shear elastic stiffness $\left(K_{t}\right)$ were calculated as the shear modulus $(G)$ divided by the cohesive element thickness, where $G$ was calculated as $E / 2(1+v)$. From tensile tests of bulk adhesive, it was found that the tensile strength ranged from 49-53 MPa [15], while the Young's modulus ranged from 2000-2300 MPa [13,15] and the Poisson ratio was 0.4 [13]. 
The mode I critical fracture energy $\left(G_{I C}\right)$ was experimentally measured using double cantilever beam test data and was found to be approximately $2.5 \mathrm{~kJ} / \mathrm{m}^{2}[18,19,20]$. G $_{\text {IIC }}$ (and hence $G_{I I I C}$ ) were obtained from the published literature [21]. The material parameter $(\eta)$ in the Benzeggagh-Kenane criterion for damage evolution was obtained from the parametric study on the MSLJ specimen under tensile loading, where at $\eta=2$, it was found that the predicted load-displacement response is closest to the experimental response $[20,22]$.

Table 1. Plasticity data for Al 2024-T3 [22]

\begin{tabular}{cccc}
\hline \multicolumn{2}{c}{ Longitudinal } & \multicolumn{2}{c}{ Transverse } \\
\hline $\begin{array}{c}\text { Yield stress } \\
(\mathrm{MPa})\end{array}$ & Plastic strain & $\begin{array}{c}\text { Yield stress } \\
(\mathrm{MPa})\end{array}$ & Plastic strain \\
\hline 300 & 0.000 & 290 & 0.000 \\
330 & 0.003 & 300 & 0.003 \\
370 & 0.015 & 340 & 0.011 \\
420 & 0.043 & 390 & 0.035 \\
440 & 0.100 & 430 & 0.100 \\
\hline
\end{tabular}

For the substrates (Al 2024-T3), the Young's modulus and Poisson's ratio was $70 \mathrm{GPa}$ and 0.33 respectively [22]. The plasticity data for this aluminium is shown in Table 1 . It should be noted that the plastic strain in longitudinal direction was obtained from tensile test of dog bone specimen where the loading is parallel to the rolling direction, whilst the plastic strain in transverse direction was obtained when the loading is perpendicular to the rolling direction.

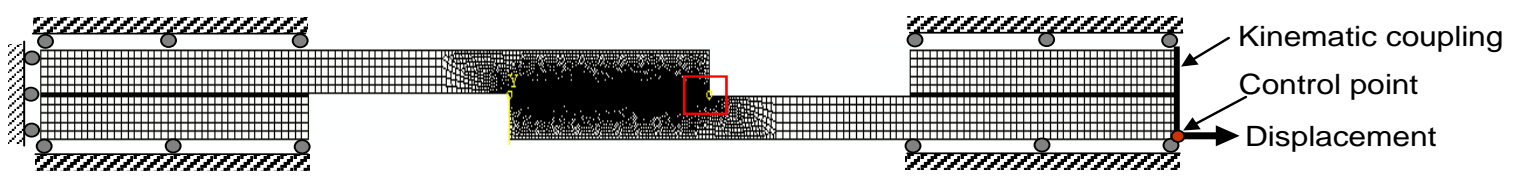




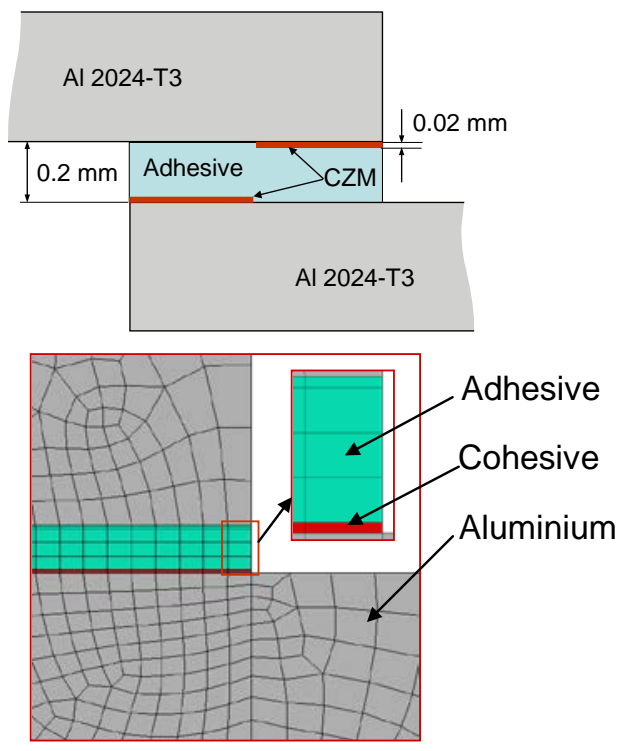

(a)

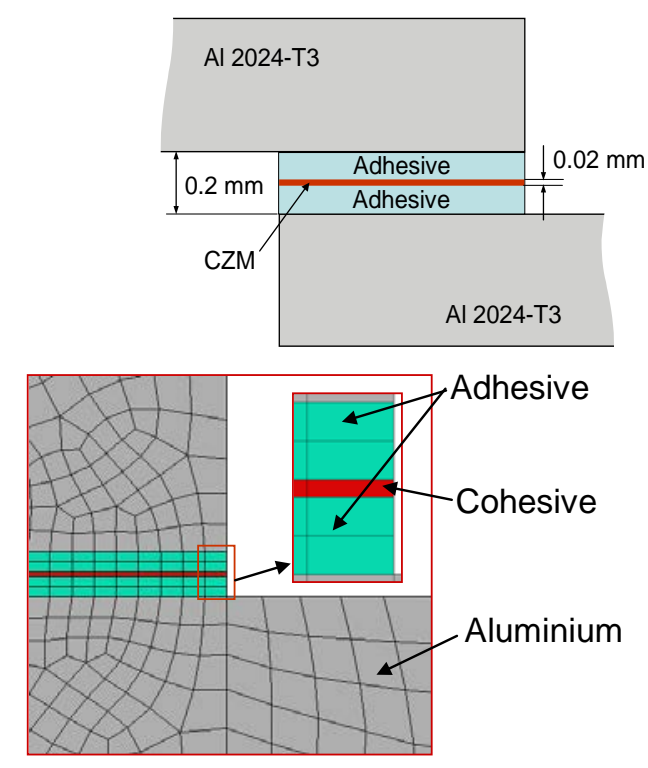

(b)

Fig. 7 The boundary conditions and mesh of the MSLJ. (a) CZM at the interface, (b) CZM at the middle (not to scale).

Fig. 7 shows the general meshing of the MSLJ and the boundary conditions. The left end was fixed, while a displacement was applied to the right end. Kinematic coupling was used on the right end to apply the displacement to a single control point, enabling the reaction force to be obtained from the same single control point. The aluminium and adhesive were modelled as 4-node quadrilateral plane stress elements (CPS4) and 4-node quadrilateral plane strain elements (CPE4) respectively. Plane strain rather than plane stress element was applied for the adhesive. It is not uncommon to model the substrate in plane stress and the adhesive in plane strain. Indeed this was the approach adopted by Goland and Reissner [23] in their pioneering analysis of single lap joints. Also this mixed 2D scheme has been shown to provide a better fit to the actual 3D results on a number of occasions [22]. The adhesive is certainly prevented from lateral contraction by the substrates, but the substrates are not so constrained. The effect of mesh size (in the range of $0.025 \times 0.02 \mathrm{~mm}$ to $1 \times 0.02$ $\mathrm{mm}$ ) on the failure load has been investigated. It was found that the failure load did not vary significantly (less than $0.5 \%$ ). Therefore, the size of CZ elements was chosen to be $0.02 \mathrm{~mm} \times 0.1 \mathrm{~mm}$. To help the convergence in the predicted response, viscosity was 
applied to the cohesive zone element. The viscosity of the cohesive zone model was 0.0001 $\mathrm{Ns} / \mathrm{m}$ as this value gave consistent convergence without affecting the predicted failure load (which happened if higher viscosities were used) [20,24].

Table 2. The baseline properties of CZM

\begin{tabular}{clllllllll}
\hline $\begin{array}{c}K_{n}{ }^{a} \\
\left(\mathrm{~N} / \mathrm{mm}^{3}\right)\end{array}$ & $\begin{array}{l}K_{s} \\
\left(\mathrm{~N} / \mathrm{mm}^{3}\right)\end{array}$ & $\begin{array}{l}K_{t} \\
\left(\mathrm{~N} / \mathrm{mm}^{3}\right)\end{array}$ & $\begin{array}{l}T_{n, \max }{ }^{\mathrm{a}} \\
(\mathrm{MPa})\end{array}$ & $\begin{array}{l}T_{s, \max } \\
(\mathrm{MPa})\end{array}$ & $\begin{array}{l}T_{t, \max } \\
(\mathrm{MPa})\end{array}$ & $\begin{array}{l}G_{I C}{ }^{b} \\
\left(\mathrm{~kJ} / \mathrm{m}^{2}\right)\end{array}$ & $\begin{array}{l}G_{I I C}{ }^{c} \\
\left(\mathrm{~kJ} / \mathrm{m}^{2}\right)\end{array}$ & $\begin{array}{l}G_{I I I C}{ }^{c} \\
\left(\mathrm{~kJ} / \mathrm{m}^{2}\right)\end{array}$ & $\eta^{d}$ \\
\hline 100000 & 35750 & 35750 & 49 & 28 & 28 & 2.5 & 5 & 5 & 2 \\
\hline
\end{tabular}

The calibration of the CZM parameters in the mixed mode configuration was performed with a MSLJ specimen using the backface strain (BFS) as a means of assessing the cohesive properties, the damage process and also to gain more understanding of the effect of factors such as substrate plasticity (see Table 1), position of CZ elements, values of traction and fracture energy and the adhesive fillet on the predicted static response. Experimentally, the failure load of the MSLJs was found (from 4 samples) to range between $3.77 \mathrm{kN}$ to $4.05 \mathrm{kN}$ with an average value of 3.93kN. However, the specimen used in the calibration had a lower value of failure load $(3.77 \mathrm{kN})$ than the batch average. This specimen was used as it had the most complete BFS data and damage process characterisation. The predicted load-displacement and load-BFS response using CZM properties as shown in Table 2 correlated well with this experimental result (from the specimen with failure load of $3.77 \mathrm{kN}$ ), with the substrate plasticity data in the longitudinal direction (see section 4.1.1), and with the CZM in the middle of adhesive layer (see section 4.1.2). Thus these data were adopted as baseline parameters and were used throughout the MSLJ FE modelling except when stated otherwise.

For use in predicting the LDB response it was necessary to adjust the CZM parameters to match the MSLJ batch averaged response (3.93 kN not $3.77 \mathrm{kN}$ used above). This was 
achieved by adjusting the critical traction values. When $T_{n, \max }$ was $53 \mathrm{MPa}$ (and thus $T_{s, \max }$ 30.5 MPa, retaining the von Mises assumption) the predicted load of MSLJ specimen (3.95 $\mathrm{kN})$ corresponded closely to the experimental batch average value (3.93 kN). Therefore, these revised tractions values will be used in the validation of the CZM properties with the final configuration (LDB specimen, see section 4.2).

\subsubsection{Effect of substrate plasticity}

In the calibration modelling above substrate plasticity was included in all models. This section considers the effect of substrate plasticity on the predicted response. Fig. 8a shows the effect of different substrate plasticity models (transverse and longitudinal) on the predicted backface strain-load curve. The strain gauges were located $2 \mathrm{~mm}$ inside both overlap ends and the backface strain is seen to increase with increasing plastic strain (ductility) of the substrate. In the case when the substrate had no plastic strain ("without plasticity"), the backface strain-load curve did not show the same non-linearity at around 3 $\mathrm{kN}$ as the other cases. However, for the two plasticity models, when load exceeded $3 \mathrm{kN}$ there was significant plasticity and the backface strain-load curve became more non-linear. The extent of non-linearity was related to the extent of plastic strain in the substrate. The transverse plasticity model generated more strain than the longitudinal plasticity model at a given level of stress (see Table 1). The backface strain-load curve when longitudinal plasticity was used was in good agreement with the experimental result; therefore it was used in all further MSLJ FE modelling.

Fig. 8b shows the damage state $(D)$ in the adhesive along the overlap length at the same load level $(3.5 \mathrm{kN})$ for the 3 different substrate material models. It is clear that there is no significant difference between the curves. This implies that the plastic strain in the 
substrate did not contribute significantly to the adhesive damage process but contributed to the backface strain.

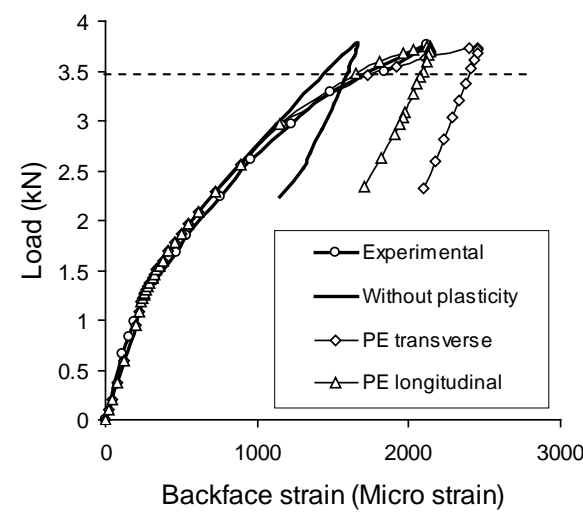

(a)

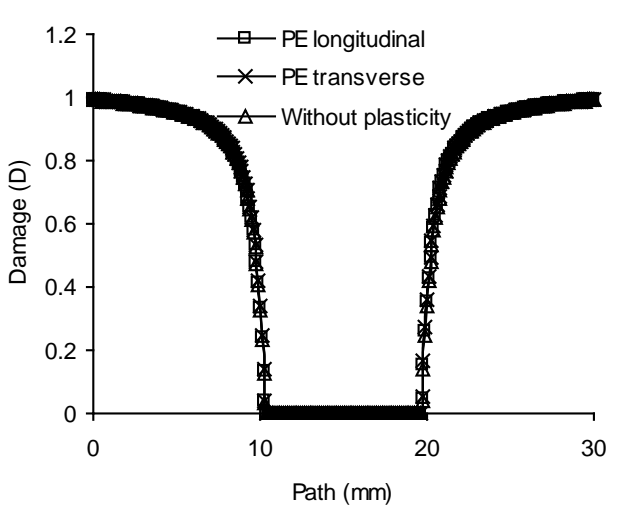

(b)

Fig. 8 (a) Backface strain-load curves of MSLJ, (b) Damage state at load of $3.5 \mathrm{kN}$ at various plasticity of substrate.

\subsubsection{Effect of position of CZM in the adhesive layer}

There are many possibilities for positioning the CZM element within the adhesive layer; (i) treating the complete thickness of adhesive layer as the CZM (continuum approach), (ii) putting the CZM on the interface between adhesive and substrate (local approach) and (iii) putting the CZM element in the middle of the adhesive layer (mixed approach). Treating the complete thickness of the adhesive layer as the CZM is the most practical and easiest approach, but also the least realistic. Therefore, only the latter two positions were studied as shown in Fig. 7.

Table 3. The failure load and displacement of MSLJ for different CZM positions

\begin{tabular}{lcc}
\hline & $\mathrm{P}_{\max }(\mathrm{kN})$ & $\begin{array}{c}\text { Displacement at } \\
\text { peak point }(\mathrm{mm})\end{array}$ \\
\hline Experimental & 3.77 & 0.43 \\
CZM at the middle & 3.75 & 0.4 \\
CZM at the interface & 3.73 & 0.4 \\
\hline
\end{tabular}




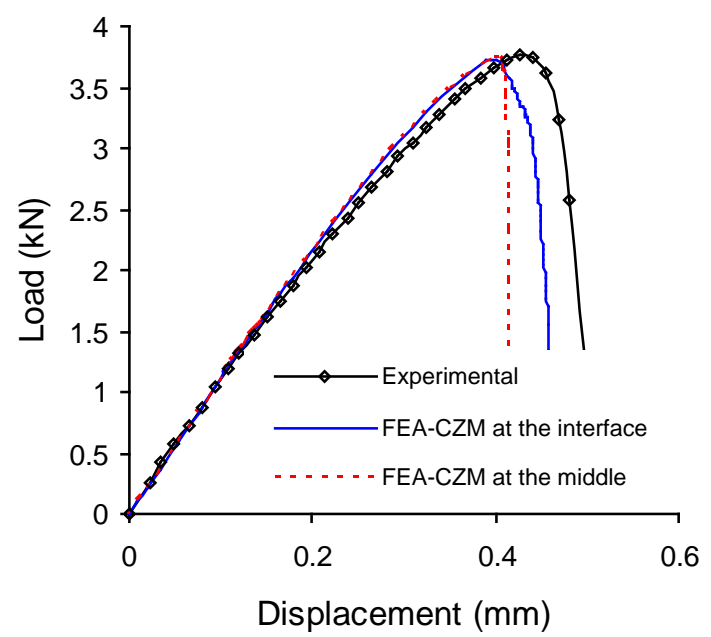

(a)

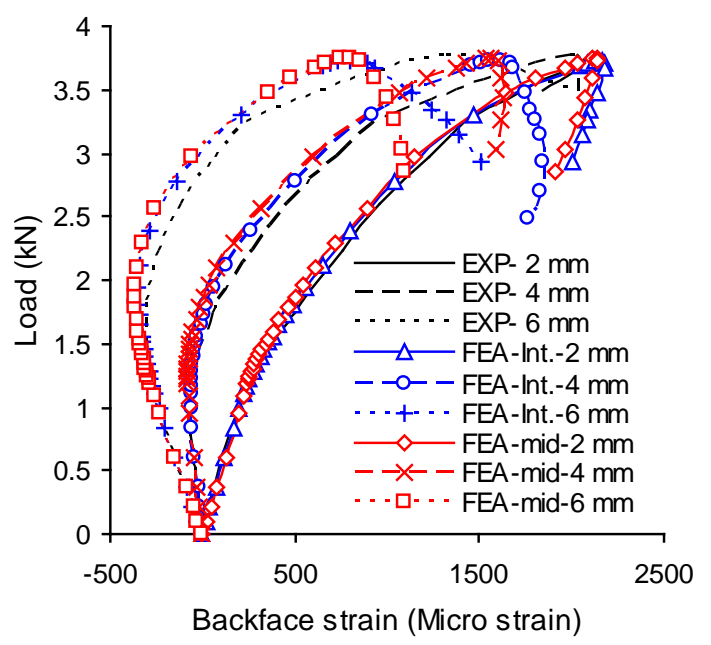

(b)

Fig. 9 (a) Load-displacement curve, (b) Backface strain-load curve for MSLJ; with CZM at different positions.

Fig. 9a shows a comparison of the experimental and FE predicted load-displacement curves. Generally, the FE predicted load-displacement response for both CZM positions shows a good agreement with the experimental result. The FE predicted load-displacement curve is in excellent agreement when the load is less than approximately $1.5 \mathrm{kN}$ and beyond that value it started to rise slightly above the experimental curve. The FE predicted displacement at the peak point is slightly lower than the experimental result (Table 3). This is possibly due to the load train compliance of the machine and grips. Fig. 9b shows the experimental and FE predicted backface strain-load response. The gauges were located at 2 $\mathrm{mm}, 4 \mathrm{~mm}$ and $6 \mathrm{~mm}$ inside the end of the overlap. In general a good agreement was found between experiment and FE modelling (both cases). At $2 \mathrm{~mm}$, the agreement was excellent, however at 4 and $6 \mathrm{~mm}$ the predicted backface strain is slightly lower than the experiment at the same load. The backface strain-load curve with the CZM located at the interface is in slightly better agreement with the experimental data. As with the loaddisplacement curves, excellent agreement was obtained at loads less than $1.5 \mathrm{kN}$, beyond that value the FE predicted backface strains were a little lower than experimental values. 


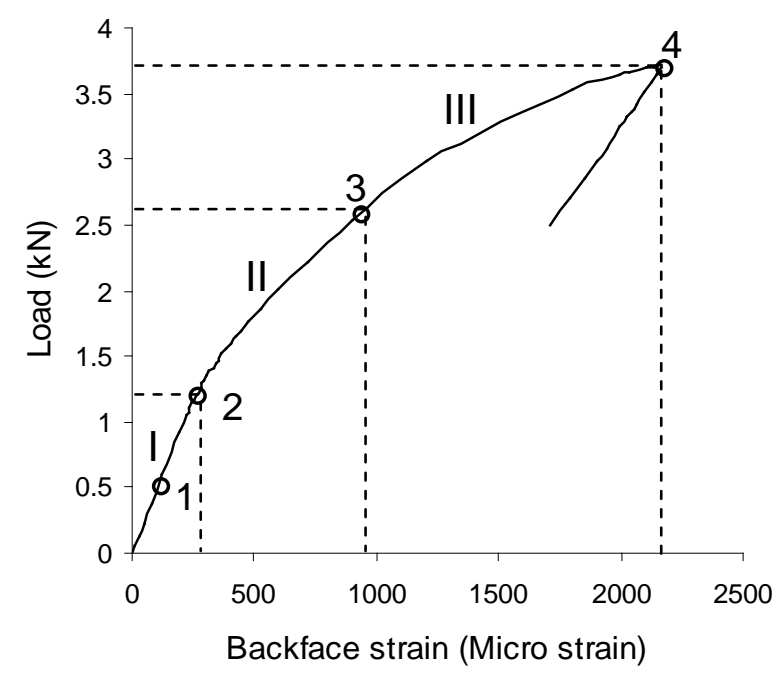

(a)

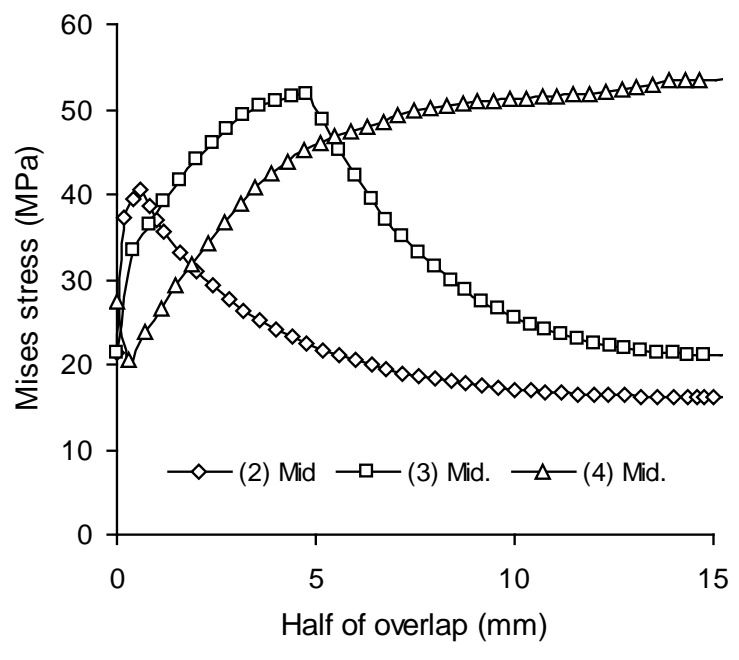

(b)

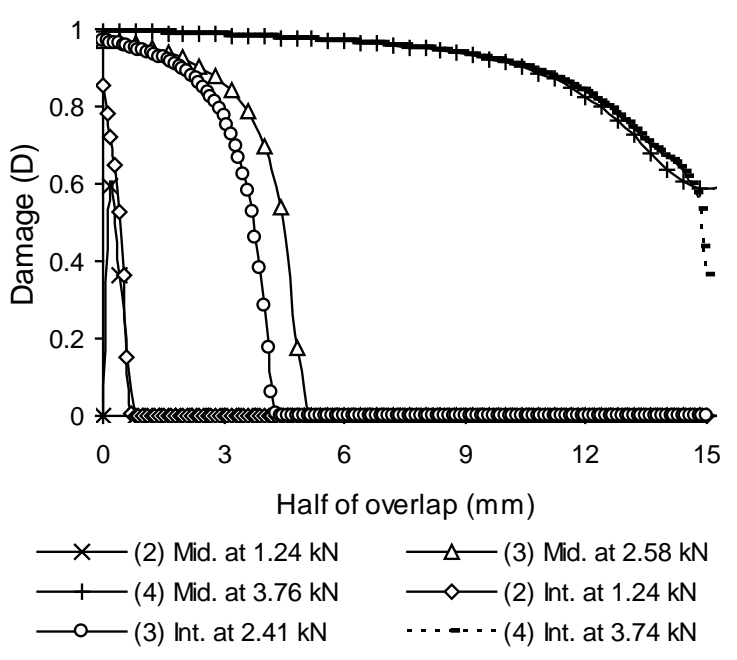

(c)

Fig. 10 (a) FE predicted backface strain-load curve (CZ in middle), (b) von Mises stress along half of the overlap (CZ in middle), (c) Damage state $(D)$ along half of the overlap (CZM in middle and interface). The distance in Figs. 10b and c are taken from the overlap end.

Fig. 10a shows the backface strain-load curve with the selected points indicating the damage process. The von Mises stress and damage state $(D)$ plots at points corresponding to those indicated on Fig. 10a are shown in Figs. 10b and c respectively. The plots were taken from the middle of adhesive layer (the interface between adhesive solid element and cohesive element). At point $\mathbf{1}$, no damage is observed in the cohesive zone (region I). 
Damage initiated at the end of the overlap at a load of approximately $1 \mathrm{kN}$, however the backface strain-load curve remains linear until point $\mathbf{2}$. It is probable that the damage is still too small $(D=0.1)$ and localised $(0.3 \mathrm{~mm}$ inside the end of the overlap, Fig. 10c) so that its effect cannot be detected by the strain gauge. At point $\mathbf{2}$ (the start of region II), the slope of the predicted backface strain-load curve starts to change. This indicates that the damage level increases and propagates towards the centre of the joint at a slow rate. The backface strain-load curve from point $\mathbf{2}$ to just beyond point $\mathbf{3}$ has a very gradually reducing slope and it can be seen from Fig. 10c that the damage increases at the overlap ends. At point 3, the aluminium adjacent to the corner of overlap also starts to deform plastically. The progression of plastic strain with increasing load along the interface region of aluminium around the overlap end can be seen in Fig. 11 . When the load reached nearly $3 \mathrm{kN}$, the slope of backface strain-load reduces more noticeably, indicating that the aluminium plastic deformation is significant and can be readily detected by strain gauge (region III). This continues until the failure occurs (after the peak load (point 4)), indicated by a longer damage zone as shown in Fig. 10c. The von Mises stress in the cohesive zone reached a maximum value at the damage tip (where initiation occurred) and decreased according to the level of damage (Fig. 10b). The predicted damage zone length at the peak load was in agreement with the visible damage in experimental when $D \geq 0.97$, which is approximately $4.6 \mathrm{~mm}$. The damage close to the middle of joint is smaller with the CZM at the interface than in the middle of the layer. This explains why the load-displacement curve after the peak point is more abrupt with the CZM in the middle than on the interface (Fig. 9a) as the joint is still able to carry further load before collapse. This is similar to the experimental load-displacement curve, however locating the CZM in the centre of the layer is more appropriate because the mode of failure of the MSLJ specimens is cohesive in the 
adhesive. Therefore, the CZM located in the middle of adhesive layer was used to model all further joints except when stated otherwise.

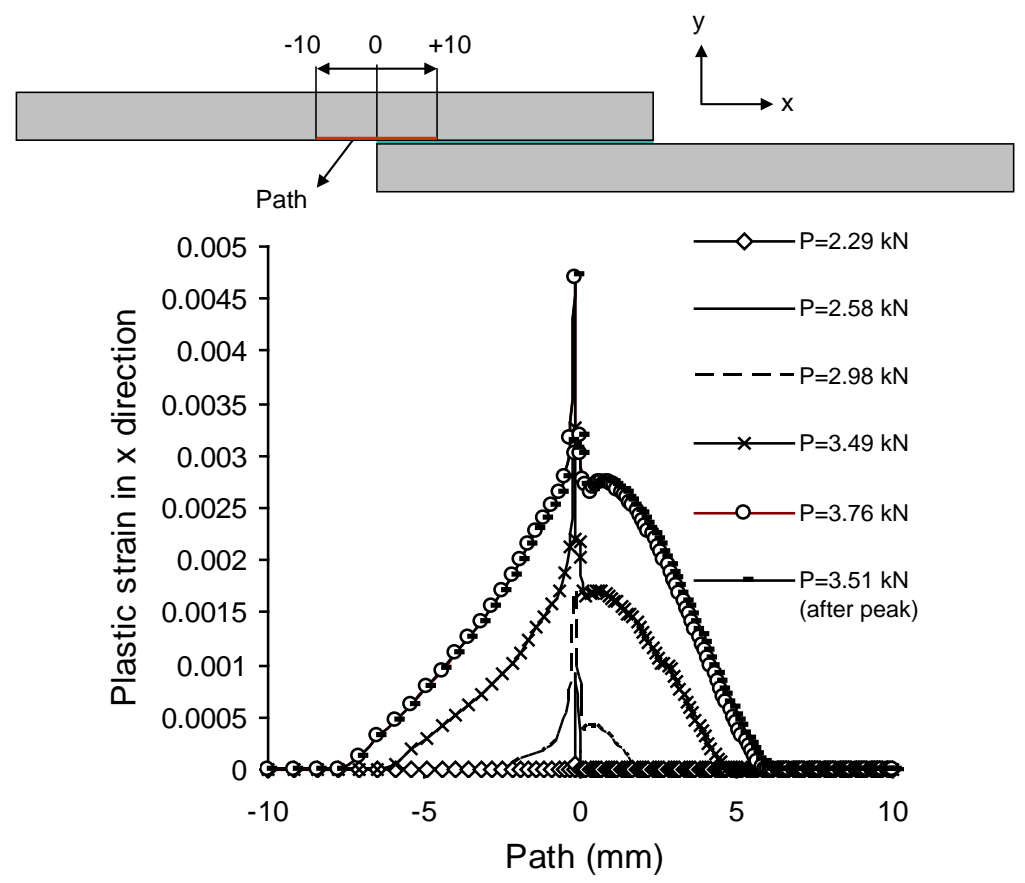

Fig. 11 The evolution of plastic strain in $\mathrm{x}$ direction with load at the interface of aluminium along overlap around the overlap end.

\subsubsection{Effect of traction and fracture energy}

Fig. 12 shows the effect of traction on the predicted failure load of MSLJ at two fracture energies. At a higher fracture energy $\left(G_{I C}=2.5 \mathrm{~kJ} / \mathrm{m}^{2}\right)$, a traction between $49-55 \mathrm{MPa}$ gave the load of failure in range of experimental results $(3.77-4.05 \mathrm{kN})$, while at a lower fracture energy $\left(G_{I C}=1.4 \mathrm{~kJ} / \mathrm{m}^{2}\right.$ ), high tractions (90 MPa) were required for the predicted load to match the experimental results. The traction value (49-55 MPa) at high fracture energy is also in the range of tensile strength of bulk FM 73M OST (49-53 MPa), while for low fracture energy the traction value is well beyond the tensile strength of bulk FM 73M OST. The shapes of the curves in Fig. 12 are related to the size of the damage zones. At low tractions the damage zone is extensive and the predicted load is mainly controlled by 
the traction. However, at higher tractions, the damage zone is smaller and the failure is more controlled by the fracture energy. This is consistent with the finding of Banea and da Silva [25] when the damage zone occupies more of the overlap length.

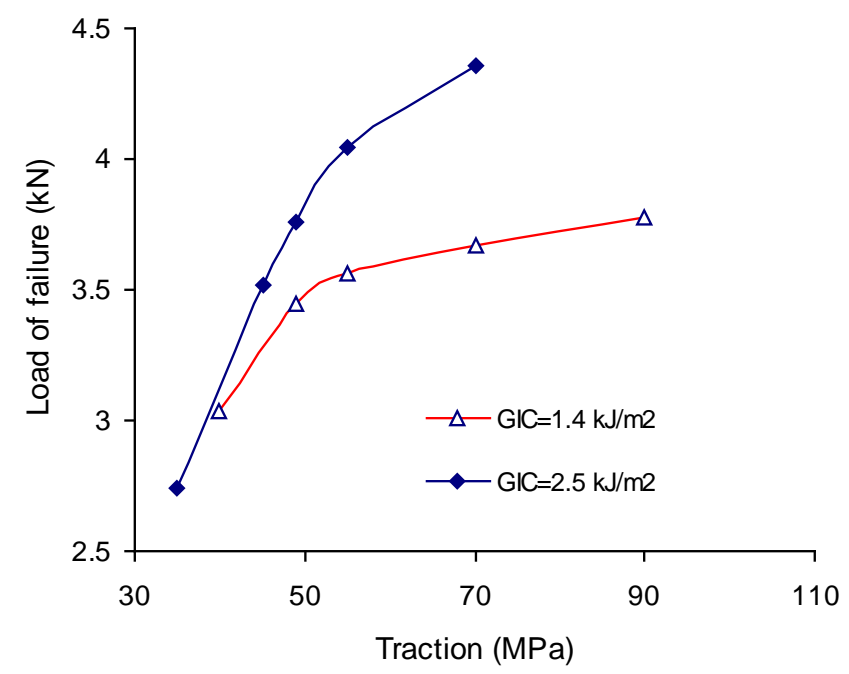

Fig. 12 Effect of traction on the predicted failure load of MSLJ.

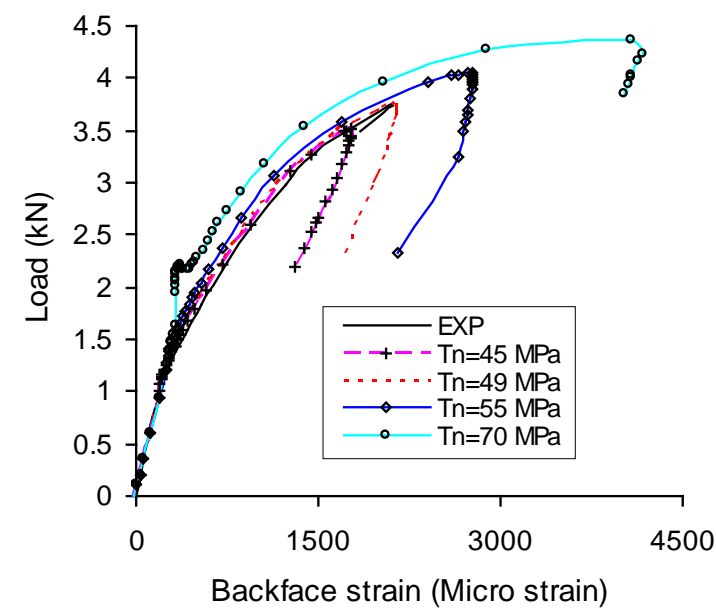

(a)

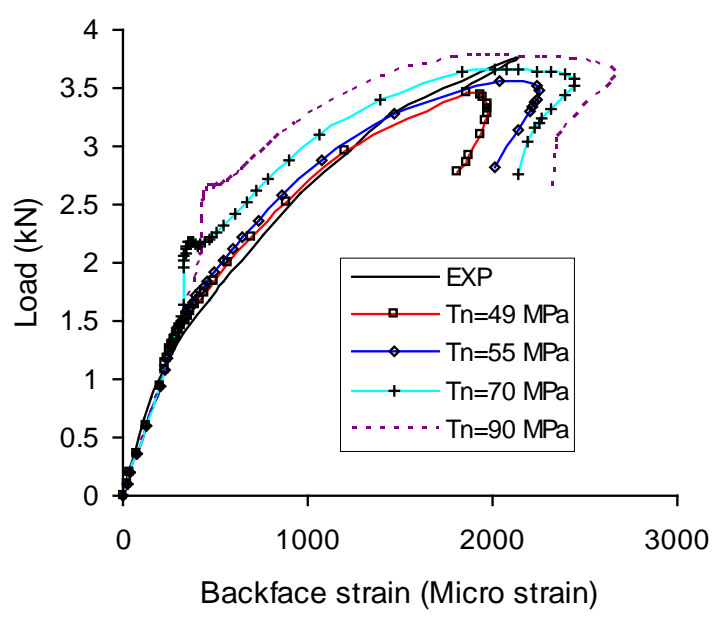

(b)

Fig. 13 Backface strain-load curves of MSLJ at various tractions (a) $G_{I C}=2.5 \mathrm{~kJ} / \mathrm{m}^{2}$, (b) $G_{I C}=1.4 \mathrm{~kJ} / \mathrm{m}^{2}$.

Fig. 13 shows the backface strain-load curve of the MSLJ for the same two normal fracture energies for different tractions. At the normal fracture energy of $2.5 \mathrm{~kJ} / \mathrm{m}^{2}$ (Fig. 13a), with the normal tractions between 45-55 MPa, the FE backface strain-load curves correlate in 
shape with the experimental results. However, the failure load only matches the experimental data at a traction of $49 \mathrm{MPa}$. At higher tractions (70 MPa), damage initiates more slowly and the backface strain tends to be lower than the experimental data at the same load. The kink that occurs at the high tractions in Fig. 13 (a and b) is caused by the complex pattern of failure which starts just inboard of the overlap end and propagates in both directions at these high tractions. This is more obvious at the lower fracture energy of $1.4 \mathrm{~kJ} / \mathrm{m}^{2}$ (Fig. 13b), where a high traction is needed to match the predicted failure load with the experimental result. Furthermore, when achieving the required failure load the predicted backface strain curve is much higher than the experimental value and there is generally not a good fit between the two. This clearly shows the benefit of using backface strain as a means of achieving a unique calibration of the cohesive zone model parameters.

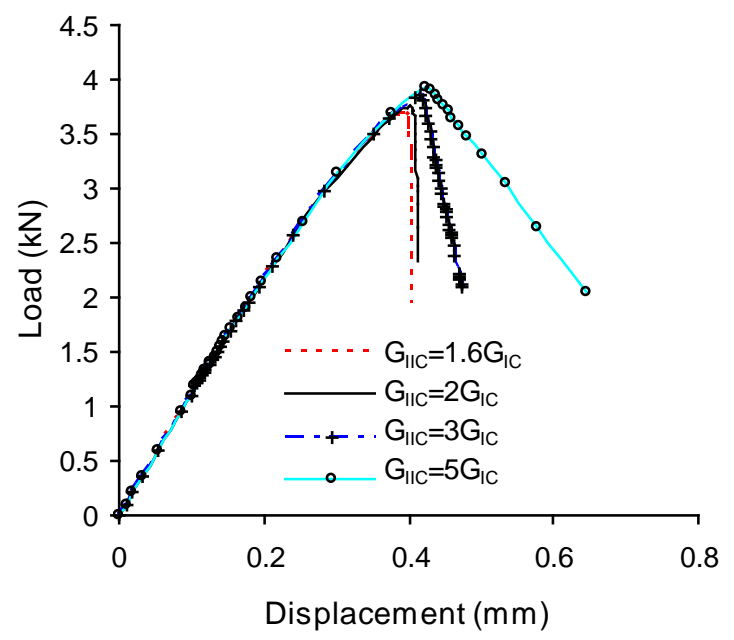

(a)

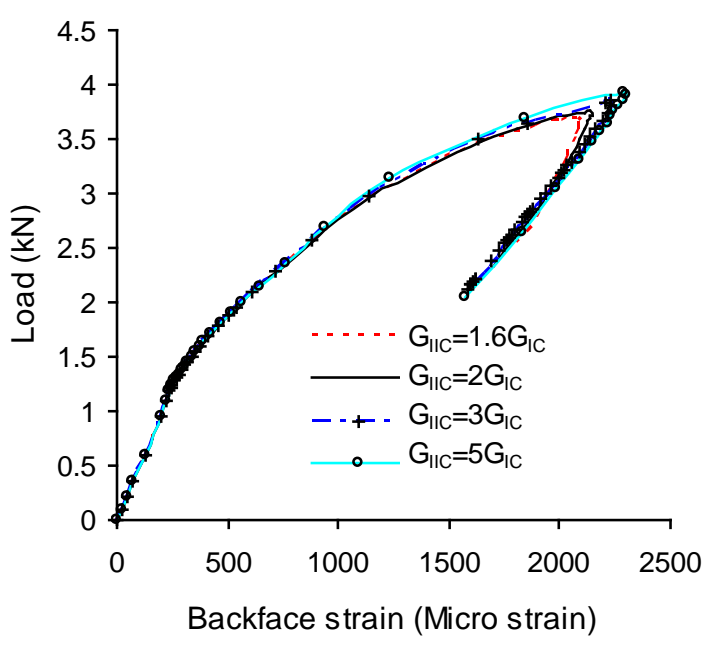

(b)

Fig. 14 (a) Load-displacement curves of MSLJ at various $G_{I I C}$, (b) Backface strain-load curves of MSLJ at various $G_{I I C}$; (both with a $G_{I C}=2.5 \mathrm{kN}$ and at a normal traction of 49 $\mathrm{MPa})$.

Fig. 14 shows the load-displacement curves and backface strain-load curves at various shear fracture energies $\left(G_{I I C}\right)$ at a normal traction of $49 \mathrm{MPa}$ and $G_{I C}$ of $2.5 \mathrm{~kJ} / \mathrm{m}^{2}$. It appears that if the $G_{I I C}$ is higher than $2 G_{I C}\left(5 \mathrm{~kJ} / \mathrm{m}^{2}\right)$, in addition to the peak load 
increasing, the load-displacement curve after peak load tends to drop slowly (Fig. 14a).

The backface strain-load curves show that the maximum backface strain increased with an increase of $G_{I I C}$ (Fig. 14b). The $G_{I I C}$ was not measured in this research, however Hafiz et al. [21] found that $G_{I I C}$ for FM 73M OST to be $1.76 G_{I C}$. The relationship between predicted failure load and the cohesive zone model parameters is complex. In Fig 14 we are operating at the upper end of the region where traction controls the predicted failure load more than fracture energy and thus the influence of $G_{I I c}$ in Fig 14 will be modest. .

\subsubsection{Effect of the fillet}

There were small adhesive fillets at the overlap ends in the MSLJ. The bonding between the perpendicular end of substrate and the fillet is weak as the substrate surface here was not treated in the same way as the bonding surfaces. Campilho et al. [26, 27] showed that XFEM (extended finite element method) successfully predicted the pure mode-I crack propagation in a DCB. XFEM can be considered to be similar to CZ modelling without it being necessary to define the crack path a-priori. The concept of XFEM is basically similar to the traction-separation law of the cohesive model; however it uses a solid continuum element rather than a cohesive element and does not require the crack path to be predefined and the mesh is automatically partitioned during damage growth. The detail of this XFEM can be found elsewhere in [16]. Therefore, in this section, the fillet was modelled using XFEM and the damage in the adhesive layer was modelled using CZM. An alternative approach would have been to have used different CZM elements on the weaker end interface. Both approaches will be able to simulate the weaker interface but the use of XFEM enables a combination of the two techniques to be considered. 
As can be seen in Fig. 15a, the fillet and the small region of the adhesive layer (approximately $0.2 \mathrm{~mm}$ inside the end of the overlap) were modelled using XFEM (area inside the dashed line). The small region under the overlap was included to allow the crack propagation from the fillet into the adhesive layer. The fillet was a right triangle with side length of $0.5 \mathrm{~mm}$ and this matched the actual length of the fillet. The mesh size in the fillet is approximately $0.05 \times 0.05 \mathrm{~mm}$.

Table 4. The properties of XFEM for FE model of fillet.

\begin{tabular}{ccccccc}
\hline & $\begin{array}{c}\text { Young's } \\
\text { modulus }\end{array}$ & $\begin{array}{c}\text { Poisson's } \\
\text { ratio }\end{array}$ & $\begin{array}{c}\text { Maximum } \\
\text { principal stress } \\
(\mathrm{MPa})\end{array}$ & $\begin{array}{c}G_{I C} \\
\left(\mathrm{~kJ} / \mathrm{m}^{2}\right)\end{array}$ & $\begin{array}{c}G_{I I C} \\
\left(\mathrm{~kJ} / \mathrm{m}^{2}\right)\end{array}$ & $\begin{array}{c}\text { Damage } \\
\text { stabilisation } \\
(\mathrm{Ns} / \mathrm{m})\end{array}$ \\
\hline Case I* & 2300 & 0.4 & 49 & 2.5 & 5 & 0.0001 \\
Case II** & 1314 & 0.4 & 15 & 0.76 & 1.52 & 0.0001 \\
\hline * Good fillet, ** Weak fillet & & \multicolumn{3}{c}{}
\end{tabular}

The damage initiation for XFEM used a maximum principal stress criterion with the initial elastic stiffness the same as the Young's modulus of the adhesive. The damage evolution followed the same method as the cohesive zone model, i.e Benzeggagh-Kenane (BK) criterion. If the fillet was well bonded to the end of substrate (good fillet, Case I) the maximum principal stress and fracture energy would be similar to the adhesive values (cohesive failure of the adhesive). However, the fillet was not well bonded to the end of substrate (weak fillet, Case II), and experimentally failed interfacially along that region. Thus, it was necessary to reduce all properties (Young' modulus, the maximum principal stress, the normal and shear fracture energies) by the same amount (i.e 69\% reduction) to reflect this poor bonding of the fillet, calibrating against the experimental data. Table 4 summarises the XFEM properties for both cases. 


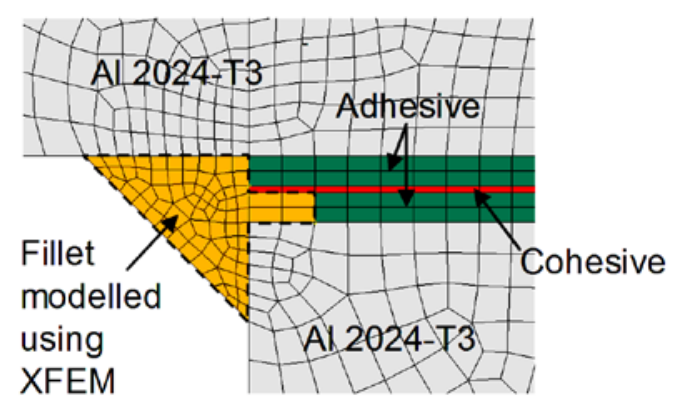

(a)

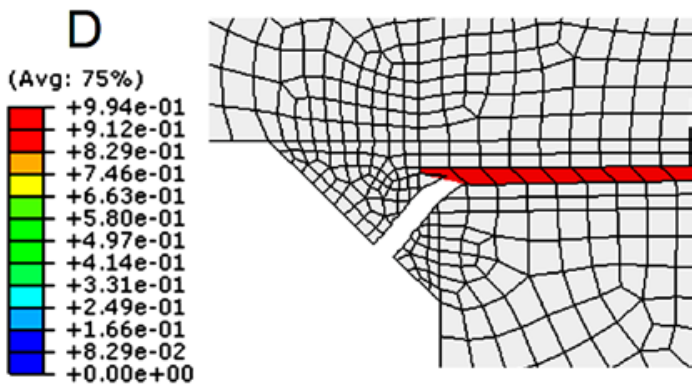

(b)

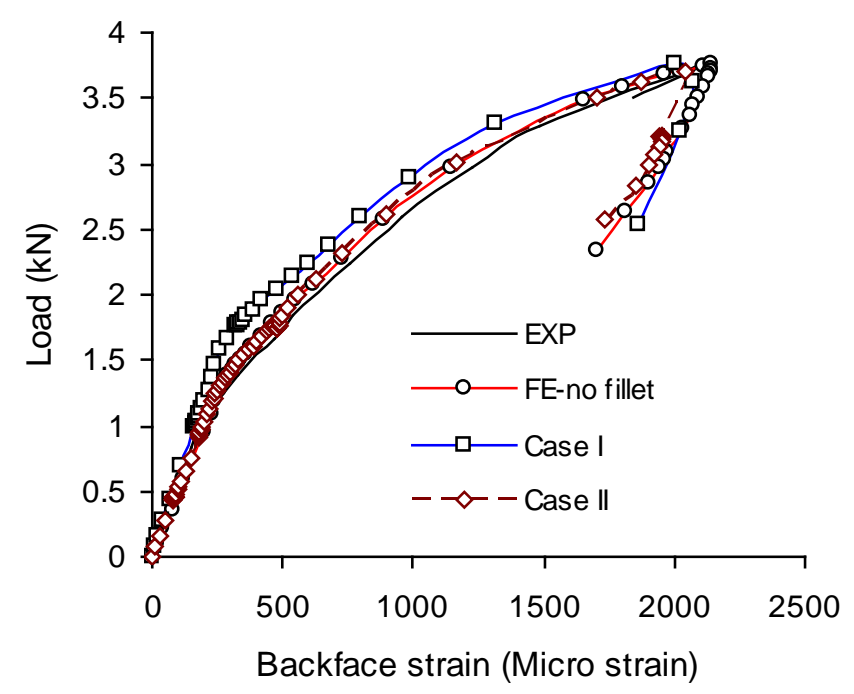

(c)

Fig. 15 (a) FE model of fillet and meshing, (b) the predicted failure path of fillet modelled using XFEM, (c) The backface strain-load curves for experimental and FE model with and without fillet.

Fig. 15c shows the experimental and FE backface strain-load curves with and without a fillet. It is seen that for a good fillet, at a given load the backface strain is lower than the experimental and the FE "without fillet" response. On the other hand for a "weak fillet", the backface strain-load curve is similar to the experimental and "without (no) fillet" FE values although the failure load is a little lower. Therefore, in subsequent modelling the fillet was not included as the results from the "weak fillet” and "without fillet” were similar. 


\subsection{Validation of CZM in laminated doubler in bending}

The CZM parameters that were discussed at the end of Section 4.1 was validated with a different joint configuration, the laminated doubler loaded in bending (LDB) (see Fig. 2). As well as the failure load, the backface strain was also obtained for the LDB and used as additional validation data.

The LDB was modelled in three-dimensions (3D) as a 3D model was required to model an environmentally aged LDB. This aspect is the subject of a later paper [15] and is not being considered here. As the LDB is symmetric, a quarter model was used. The boundary conditions of the model and the meshing is seen in Fig. 16. It was observed that there was a fillet at the end of stringer in the specimens. This fillet was included in the FE model. Although the fillet varies in size in the physical specimens a single typical size fillet was used in the modelling. Experimentally, the fillet size does not appear to affect significantly the static strength. The assumed shape of the fillet was a right triangle with a side length of approximately $1 \mathrm{~mm}$.

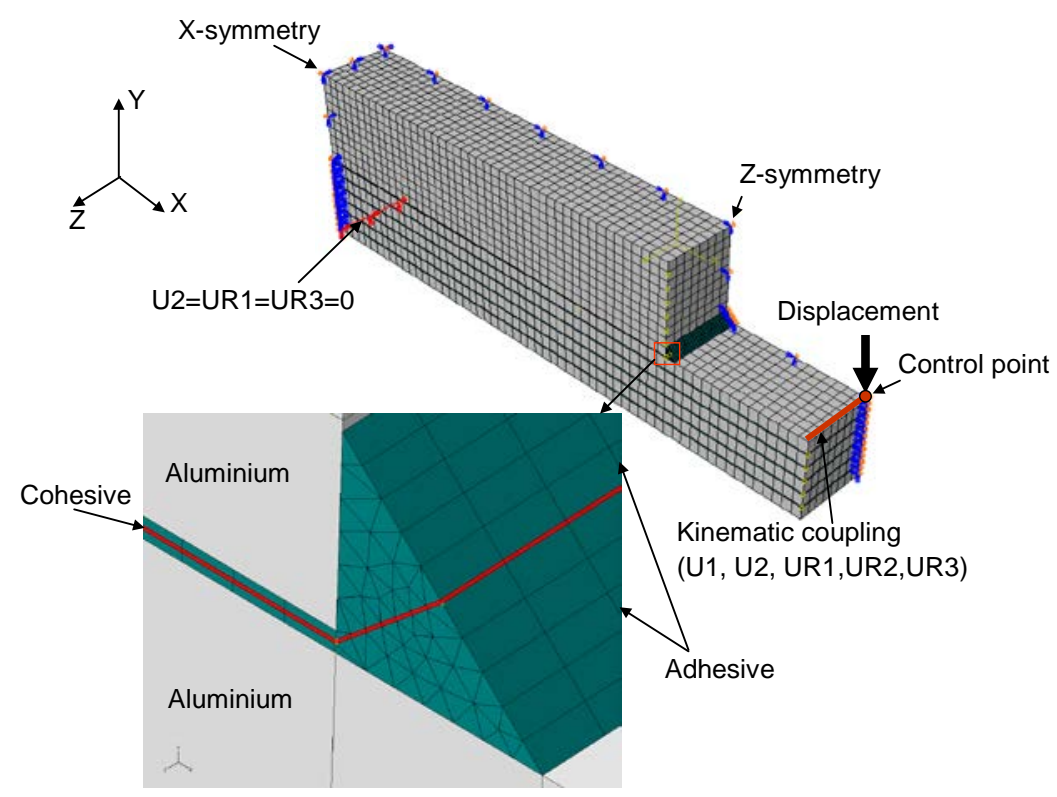

Fig. 16 The FEM boundary condition and meshing of LDB. 
As the failure in LDB was in the bondline between the laminate and stringer, the 3D cohesive element (COH3D) was used only in this bondline and not in the other bondlines in the laminate substrate. The thickness of adhesive in the bondline was taken to vary linearly, from $0.1 \mathrm{~mm}$ at the end of the overlap to $0.2 \mathrm{~mm}$ at the centre. However, the thickness of cohesive element was uniform, $0.02 \mathrm{~mm}$, and located in the middle of the adhesive layer (following section 4.1.2). To simply the FE modelling, cohesive elements rather than XFEM was also used to model the failure in the fillet. The thickness of the cohesive element in this region was also approximately $0.02 \mathrm{~mm}$. The failure path of the fillet observed experimentally was at an angle of $40-45^{\circ}$ from the laminate, therefore, the cohesive element was aligned at an angle of approximately $45^{\circ}$ from the laminate. The mesh size of CZM in the bondline and in the fillet was $0.25 \times 0.25 \mathrm{~mm}$ and $0.098 \times 0.25$ mm respectively. The aluminium layers, stringer and adhesive were modelled as 8-node linear bricks (C3D8). Tie constraints were applied between the surfaces on the bondlinestringer interface and the bondline-laminate interface, so that different mesh sizes between the substrate and bondline were possible.

As discussed in Section 4.1, the CZM properties used to model the LDB were slightly different to the properties in MSLJ. The basis for this slight adjustment are repeated here. The calibration was carried out using a MSLJ specimen that had a lower strength than the batch average. Therefore, before using with the LDB, the normal and shear tractions were increased slightly to $53 \mathrm{MPa}$ and $30.5 \mathrm{MPa}$ respectively to match the average experimental MSLJ failure load. For aluminium the elastic modulus and Poisson's ratio were the same 
as in MSLJ, however plasticity in transverse direction was used, because the laminate used in this LDB was extracted in a chordwise direction from a wing panel.

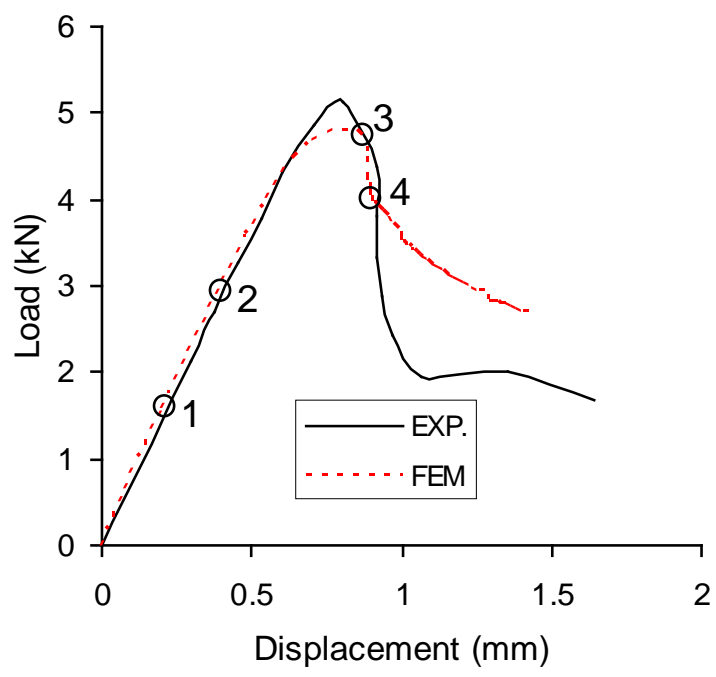

(a)

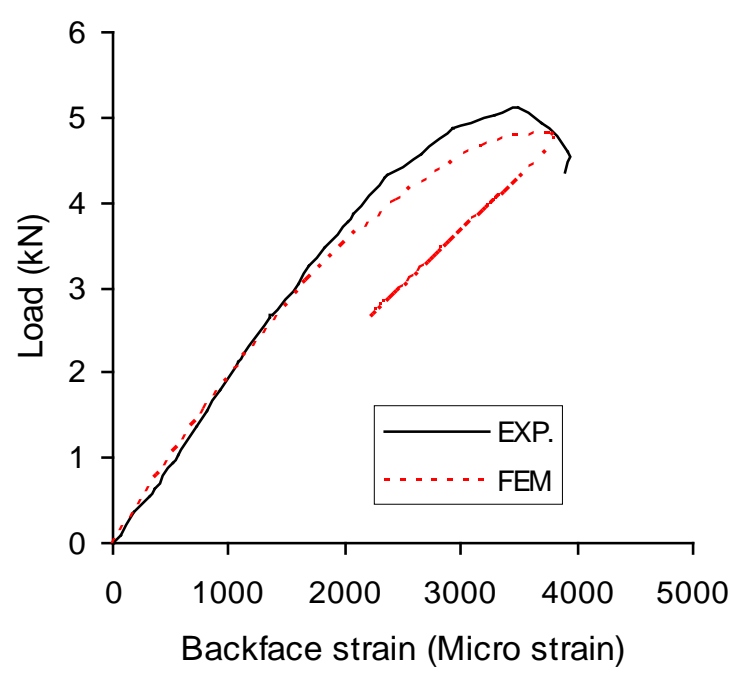

(b)

Fig. 17 Comparison of the predicted and experimental results for the LDB for a) loaddisplacement curves. The selected points indicated where the contour, shown in Fig. 18, was taken and (b) backface strain-load curves located $4 \mathrm{~mm}$ inside the overlap.

Fig. 17a shows the load-displacement curve of LDB. The experimental result is included for comparison. Generally, good agreement was found between FE and experimental results, however at high loads, the FE load-displacement curve was a little lower than the experimental data. Also, the descending part of the FE curve was a little higher than experimental data. The lower predicted failure load (4.7\%) may be a result of a slightly different manufacturing process and also the different age of adhesive in the MSLJ and the LDB. However, generally good agreement was also found between FE and experimental backface strain-load curves (Fig. 17b). The trend of the two curves was similar to the loaddisplacement curves, with the FE backface strain deviating more at high loads. Had the original CZM properties (determined from a weaker than average MSLJ) been used the resulting error in predicted strength would only have been $8 \%$. 


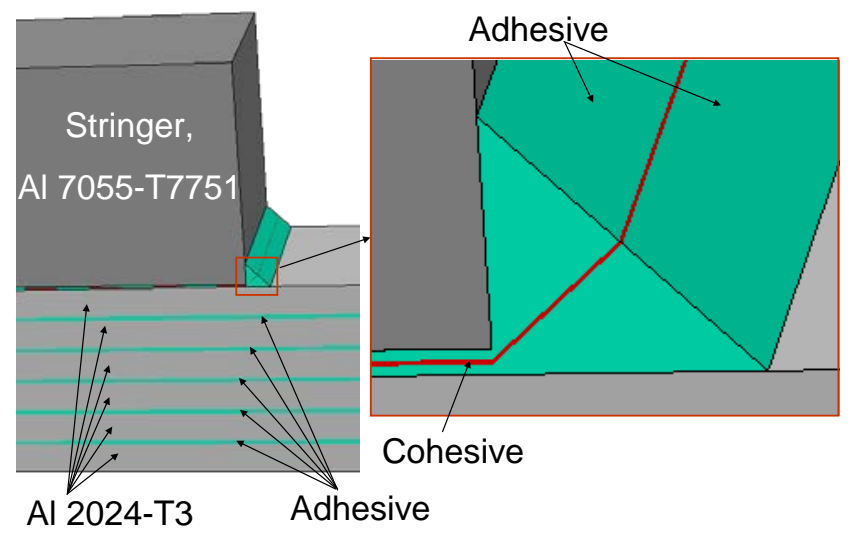

(1) S, Mises
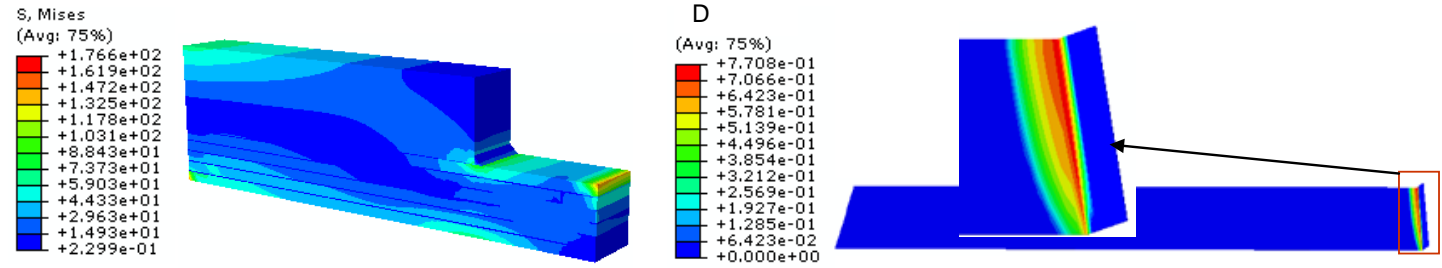

(3) $\begin{gathered}\text { S, Mises } \\ \text { (Ay }\end{gathered}$

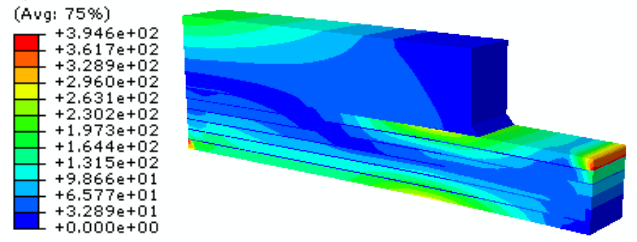

D

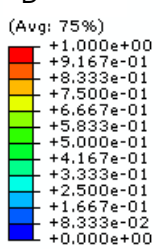

(a)

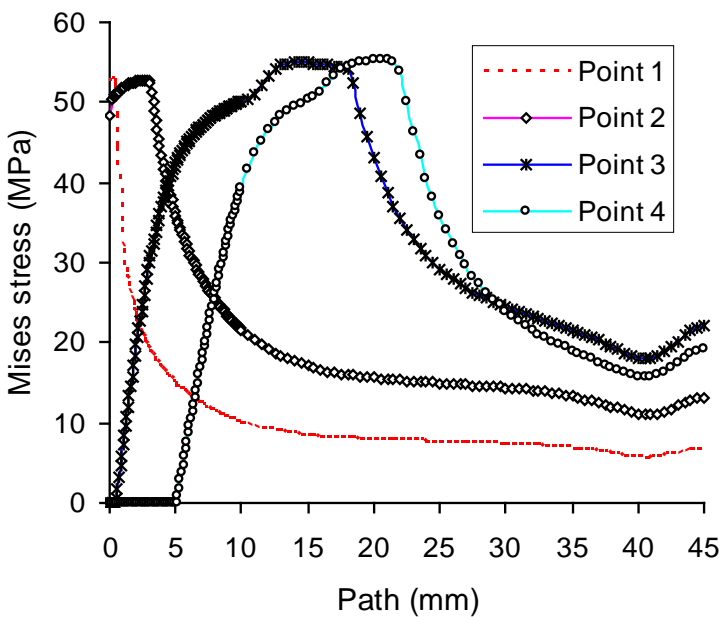

(b)

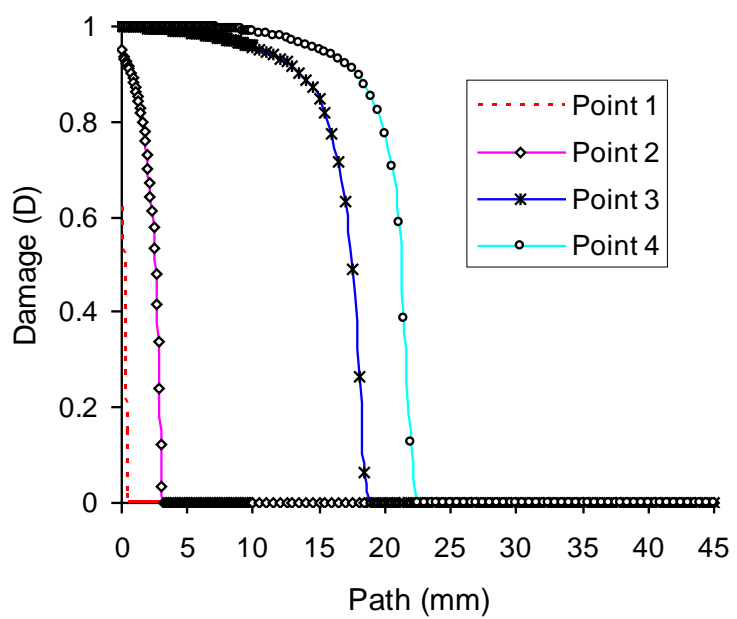

(c)

Fig. 18 (a) Contour plots of von Mises stress and damage. Only the cohesive layer is shown in the damage contour, (b) plot of von Mises stress along the overlap edge, (c) plot of damage along the overlap edge. (the numbering refers to the numbers on the plot in Fig 17)

Fig. 18a shows contour plots of von Mises stress and damage $(D)$ at the selected points shown in Fig. 17a. The distribution of the von Mises stress and adhesive damage $(D)$ along 
the overlap length are shown in Fig. 18b and Fig. 18c respectively. The plots were taken from the middle of adhesive layer (interface between adhesive solid element and cohesive element). At point 1 (approximately $1.6 \mathrm{kN}$ ), damage can be seen at the corner of the overlap end. The von Mises stress (Fig. 18b) reached the maximum traction (53 $\mathrm{MPa}$ ) at the damage tip and then decreased as the damage increased. The maximum damage in this damage area was 0.77 at the corner between end of the overlap and the fillet (at the centre of the joint), Fig. 18c. The damage then propagated stably towards the centre of the joint and into the fillet until point 2 (approximately $3 \mathrm{kN}$ ). The load-displacement and backface strain-load curves appear linear to this point. The damage zone length reached approximately $3 \mathrm{~mm}$ inside the overlap and the maximum damage was 0.96 at the corner between overlap and fillet (see Figs. 18b and c). After point 2, the load-displacement and backface strain-load curves became non linear, however this was more apparent in the backface strain-curve. This was the start of fast damage propagation within the cohesive zone to the centre of joint and into the fillet. No plastic deformation of the laminate was observed around the end of overlap, therefore the non-linearity was likely to be due to the failure of the cohesive zone. At the point 3 (peak load), the fillet has fully damaged $(D=1)$ and the entire damage zone length inside the overlap ( $D$ value between 0 and 1 ) has reached approximately $18 \mathrm{~mm}$ (Fig. 18c). Nevertheless, the observed experimental damage (around $8 \mathrm{~mm}$ ) was close to the damage length in the FE when the $D \geq 0.97$ (Fig. 18c) and this was also found in MSLJ (see section 4.1.2). At point 4, the load has dropped to approximately $4 \mathrm{kN}$, and approximately $5 \mathrm{~mm}$ inside the overlap is completely failed $(D=$ 1) and the overall length of the FE damage ( $D$ value is between 0 and 1 ) was approximately $21.5 \mathrm{~mm}$. This is the fully damaged condition and the joint cannot carry any further load. It was seen that when the damage had initiated but was not fully damaged $(0<D<1)$, the cohesive element was still able to carry some load (depending on the level of 
damage). There was no plastic deformation in the laminate close to the bondline until around the peak load. Plastic deformation was localised around the place where load and support were applied and also in the central region when the damage zone reached the centre of joint.

\section{Conclusions}

FE modelling of progressive damage in a statically loaded MSLJ using a cohesive zone model has been carried out successfully. The effects studied included: position of CZM within the adhesive layer, plasticity of the substrate, effect traction and fracture energy, and the effect of a fillet. The backface strain of the MSLJ was used as mean of calibrating the CZM properties. The CZM was then validated in a different joint configuration, the LDB. Some keys finding are summarised below:

1. The traction and fracture energy of CZM were predicted using the static strength of dumbbell FM 73M OST and fracture energy obtained from double cantilever beam (DCB) of Al 2024-T3 bonded using FM 73M OST respectively. The prediction of MSLJ using CZM with properties described above were in very good agreement with the experimental results both in terms of static strength and backface strain.

2. The position of CZM in the adhesive layer (in the middle of the adhesive or at the interface) does not have significant effect on the predicted static strength and backface strain.

3. The plasticity of the substrate does not have significant effect of the predicted static strength of MSLJ; however it has a significant effect on the predicted backface strain.

4. Increasing the critical traction tended to increase the static strength, and the predicted backface strain became lower than the experimental result at the same load. At lower tractiosn (large damage zones) the tractions control the predicted failure load whilst at 
high traction (shorter damage zones) the fracture energy control the predicted failure load. Beyond a certain value of traction, there is difficulty in initiating damage in the $\mathrm{CZ}$ at the overlap end due to the complex pattern of failure which starts just inboard of the overlap end and propagates in both directions. This is more pronounced when the lower fracture energy was used (i.e $1.4 \mathrm{~kJ} / \mathrm{m}^{2}$ ). Increasing the shear fracture energy increased the predicted strength only marginally; however, when it is higher than 2 times the normal fracture energy the load-displacement curve after peak failure tended to occur gradually rather than abruptly as observed experimentally.

5. The fillet has an effect on the backface strain. A fillet that was well bonded to the substrate edge results in the FE backface strain being lower than the experimental result, while the FE backface strain using a poorly bonded fillet is the same as having no fillet and correlates well with the experimental data

6. Validation of CZM properties calibrated using MSLJ on the LDB has been undertaken. FE predictions of the LDB using these properties correlated reasonably well with the experimental results both in terms of static strength and backface strain.

7. The backface strain technique is a useful means of calibrating the properties of a CZM and also of monitoring the damage process in an adhesively bonded joint.

\section{Acknowledgement}

The authors would like to thanks to Airbus (Bristol, UK) who supplied the laminated doubler material and for the surface treatment of aluminium. Also thanks to Directorate General of Higher Education, Ministry of Education, Republic of Indonesia who provided supporting funds for this research.

\section{References}


[1] Barenblatt GI, The formation of equilibrium crack during brittle fracture, general ideas and hypothesis. Axially-symmetric cracks. J. Applied Mathematics and Mechanics (PMM) 1959; 23(4): 1009-1029.

[2] Barenblatt GI, Mathematical theory of equilibrium cracks in brittle fracture. Advances in Applied Mechanics 1962; 7: 55-129.

[3] Yang QD, Thouless MD, Ward SM. Numerical simulation of adhesively-bonded beams failing with the extensive plastic deformation. Journal of Mechanics and Physics of Solids 1999; 47: 1337-1353.

[4] Yang QD, Thouless MD, Ward SM. Elastic-plastic mode-II fracture of adhesive joints. International Journal of Solids and Structures 2001; 38: 3251-3262.

[5] Yang QD, Thouless MD. Mixed-mode fracture analyses of plastically-deforming adhesive joints. International Journal of Fracture 2001; 110: 175-187.

[6] da Silva LFM, and Campilho RDSG. Advances in numerical modeling of adhesive joints. Heilderberg: Springer; 2012.

[7] Volokh KY. Comparison between cohesive zone models. Communication in Numerical Methods in Engineering 2000; 20: 845-856.

[8] Chandra N, Li H, Shet C, Ghonem H. Some issues in the application of cohesive zone models for metal-ceramic interfaces. International Journal of Solids and Structures 2002; 39: 1827-2855.

[9] Alfano G. On the influence of the shape of the interface law on the application of cohesive-zone models. Composite Science and Technology 2006; 66: 723-730.

[10] Abe H, Satoh T. Non-destructive detection method of fatigue crack in spot-welded joints. Yosetsu Gakkai Ronbunshu/Quarterly Journal of Japan Welding Society 1986; 4(4): 666-673. 
[11] Zhang ZH, Shang JK, Lawrence FV. A backface strain technique for detecting fatigue-crack initiation in adhesive joints. Journal of Adhesion 1995; 49(1-2): 23-36.

[12] Crocombe AD, Ong CY, Chan CM, Wahab MMA. Investigating fatigue damage evolution in adhesively bonded structures using backface strain measurement. Journal of Adhesion 2002; 78(9): 745-776.

[13] Liljedahl CDM, Crocombe AD, Wahab MMA, Aschroft IA. Modelling the environmental degradation of the interface in adhesively bonded joints using cohesive zone approach. The Journal of Adhesion 2006; 82: 1061-1089.

[14] Cytec Engineered Materials. FM ${ }^{\circledR} 73$ toughened epoxy film, Technical Service. 1300 Revolution Street, Havre de Grace. Maryland: 1998.

[15] Sugiman S, Crocombe AD, Aschroft IA. Experimental and numerical studies on the static response of aged adhesively bonded structures. Int. J. of Adhesion and Adhesives 2012; Submitted.

[16] ABAQUS. User manual, version 6.9.1. USA: Habbit, Karlsson \& Sorensen, Inc.; 2009.

[17] Benzeggagh M L, and Kenane M. Measurement of mixed-mode delamination fracture toughness of unidirectional glass/epoxy composites with mixed-mode bending apparatus. Composites Science and Technology 1996; 56: 439-449.

[18] Rider A, Chalkley P. Durability of an off-optimum cured aluminium joint. Int. J. of Adhesion and Adhesives 2004; 24: 95-106.

[19] Steinbrecher G, Buchman A, Sidess A, Sherman D. Characterization of the mode I fracture energy of adhesive joints. Int. J. of Adhesion and Adhesives 2006; 26: 644650.

[20] Sugiman. Combined environmental and fatigue degradation of adhesively bonded metal structures. PhD Thesis. University of Surrey, Guildford, UK: 2011. 
[21] Hafiz TA, Abdel Wahab MM, Crocombe AD, Smith PA. Mixed-mode fracture of adhesively bonded metallic joints under quasi-static loading. Engineering Fracture Mechanics 2010; 77: 3434-3445.

[22] Khoramishad H. Modelling fatigue damage in adhesively bonded joints. PhD Thesis. University of Surrey, Guildford, UK: 2010.

[23] Goland M and Reissner E. The stresses in cemented joints. Journal of Applied Mechanics 1994; 11: A-17-A-27,

[24] Khoramishad H, Crocombe AD, Katnam KB, Aschroft IA. Predicting fatigue damage in adhesively bonded joints using a cohesive zone model. International Journal of Fatigue 2010; 32(7): 1146-1158.

[25] Banea MD, da Silva LFM, Campilho RDSG. Mode I fracture toughness of adhesively bonded joints as a function of temperature: Experimental and numerical study. Int. J. of Adhesion and Adhesives 2011; 31: 273-279.

[26] Campilho RDSG, Banea MD, Pinto AMG, da Silva LFM, de Jesus APM. Strength prediction of single and double-lap joints by finite element modelling. Int. J. of Adhesion and Adhesives 2011; 31: 363-372.

[27] Campilho RDSG, Banea MD, Pinto AMG, da Silva LFM. Extended finite element method for fracture characterization of adhesive joints in pure mode I. Computational Materials Science 2011; 50: 1543-1549. 